\title{
FOCAL ADHESIONS, CONTRACTILITY, AND SIGNALING
}

Keith Burridge and Magdalena Chrzanowska-Wodnicka Department of Cell Biology and Anatomy, and Lineberger Comprehensive Cancer Center, University of North Carolina at Chapel Hill, Chapel Hill, North Carolina 27599-7090

KEY WORDS: integrins, ECM, cytoskeleton, Rho, kinases

\section{ABSTRACT}

Focal adhesions are sites of tight adhesion to the underlying extracellular matrix developed by cells in culture. They provide a structural link between the actin cytoskeleton and the extracellular matrix and are regions of signal transduction that relate to growth control. The assembly of focal adhesions is regulated by the GTP-binding protein Rho. Rho stimulates contractility which, in cells that are tightly adherent to the substrate, generates isometric tension. In turn, this leads to the bundling of actin filaments and the aggregation of integrins (extracellular matrix receptors) in the plane of the membrane. The aggregation of integrins activates the focal adhesion kinase and leads to the assembly of a multicomponent signaling complex. 
The adhesive interactions between a cell and its surrounding extracellular matrix (ECM) regulate its morphology, migratory properties, growth, and differentiation. One model system for studying adhesion to ECM is the focal adhesion (FA). FAs are specialized sites of adhesion developed by many cells in culture. They consist of aggregated ECM receptors (integrins) that span the plasma membrane, interacting on the outside with ECM components and on the inside with bundles of actin filaments (stress fibers). Many proteins have been identified in FAs, particularly at their cytoplasmic face. Some of these proteins have predominantly a structural role, whereas others are involved in signal transduction.

The field of FA research has grown considerably since one of us participated in writing a review on FAs for this series (Burridge et al 1988). In large part, this growth reflects the increasing interest in integrin-mediated signaling and the widely recognized effect integrin-mediated adhesion has on many aspects of cell behavior. Several excellent recent reviews cover various areas of integrinmediated signal transduction and FA research (Adams \& Watt 1993, Juliano \& Haskill 1993, Hemler et al 1994, Pavalko \& Otey 1994, Clark \& Brugge 1995, Yamada \& Miyamoto 1995, Ridley 1995, Richardson \& Parsons 1995), including two in Volume 11 of this series (Jockusch et al 1995, Schwartz et al 1995). Our intention here is to avoid repetition of these reviews. Thus we focus on one topic generally neglected: the relationship between contractility/isometric tension and the formation of FAs. We believe that this is an area critical to understanding not only the assembly of these structures but also the signaling that occurs within them. In this context, we discuss the low molecular weight GTP-binding protein Rho, which stimulates the formation of FAs and stress fibers and whose mode of action has generated considerable interest.

\section{STRUCTURAL ORGANIZATION OF FOCAL ADHESIONS}

Many of the structural details of FAs have been reviewed recently (Jockusch et al 1995). Structural proteins in FAs are listed in Table 1. Several appear to be 
Table 1 Structural components of focal adhesions

\begin{tabular}{|c|c|c|c|}
\hline \multicolumn{2}{|l|}{ Transmembrane } & \multicolumn{2}{|l|}{ Cytoplasmic } \\
\hline 1. integrins & 4. actin & 10. zyxin & 16. aciculin* \\
\hline 2. syndecan IV & 5. $\alpha$-actinin & 11. CRP & 17. dystrophin* \\
\hline \multirow[t]{4}{*}{ 3. dystroglycan* } & 6. filamin & 12. radixin & 18. syntrophin* \\
\hline & 7. vinculin & 13. fimbrin & 19. utrophin* \\
\hline & 8. talin & 14. profilin & \\
\hline & 9. tensin & 15. VASP & \\
\hline \multicolumn{4}{|c|}{$\begin{array}{l}\text { Components marked with an asterisk are found only in the FAs of specialized } \\
\text { cells types. 1. reviewed by Hynes 1992; 2. Woods \& Couchman 1994; } 3 . \\
\text { Belkin \& Smalheiser 1996; 4. Geiger 1979; 5. Lazarides \& Burridge 1975, } \\
\text { Wehland et al 1976; 6. Mittal et al 1987, Pavalko et al 1989; 7. Geiger 1979, } \\
\text { Burridge \& Feramisco 1980; 8. Burridge \& Connell 1983; 9. Wilkins et al } \\
\text { 1986, Wilkins et al 1987, Bockholt et al 1992; 10. Beckerle 1986; 11. Sadler } \\
\text { et al 1992; 12. Sato et al 1992; 13. Bretscher 1981; 14. listed here because } \\
\text { of the binding to VASP; Reinhard et al 1995a; 15. Reinhard et al 1992; } 16 . \\
\text { Belkin et al 1994; 17, 18. Kramarcy \& Sealock 1990; 19. Belkin \& Burridge } \\
\text { 1995. }\end{array}$} \\
\hline
\end{tabular}

universal FA constituents, whereas others are cell-type specific (e.g. dystrophin, aciculin, etc). It has not been determined whether some of these components have structural or signaling functions.

\section{Integrins and Other Transmembrane Components}

The major transmembrane components in FAs are integrins, a large family of transmembrane heterodimers (Hynes 1992). Integrins are classified into several families according to their $\beta$ subunits. Most $\beta$ chains can pair with multiple $\alpha$ subunits, and a few $\alpha$ subunits pair with more than one $\beta$ subunit (Hynes 1992). The $\alpha$ and $\beta$ subunits each span the membrane once and have large extracellular and short intracellular domains (with the exception of the $\beta_{4}$ cytoplasmic domain, which is 1000 amino acids long and interacts with the intermediate filament cytoskeleton rather than with microfilaments). Most of the integrins involved in formation of focal adhesions are members of the $\beta_{1}$ or $\beta_{3}$ families. Pairing different $\alpha$ subunits with these $\beta$ chains generates receptors for many different ECM proteins. A major requirement for FA development is that the ECM provides a ligand for integrins expressed on the cell surface. The type of integrin found within focal adhesions is generally dictated by the ECM to which cells adhere (Singer et al 1988, Dejana et al 1988, Fath et al 1989). However, a situation has been described in which a laminin-binding integrin, $\alpha_{6} \beta_{1}$, not known to interact with fibronectin, was detected in the FAs of cells adhering to fibronectin (Cattelino et al 1995). For cells grown in serum, vitronectin is typically the ECM protein adsorbed to the glass or plastic substratum, and cells expressing the vitronectin receptor $\alpha_{v} \beta_{3}$ will develop FAs containing this integrin. Probably the most frequently studied FAs are those 
made by cells plated on surfaces coated with fibronectin. These FAs involve the major fibronectin receptor $\alpha_{5} \beta_{1}$.

Both the vitronectin receptor $\alpha_{\mathrm{v}} \beta_{3}$ and the fibronectin receptor $\alpha_{5} \beta_{1}$ recognize the sequence RGD within their respective ligands (Hynes 1992; Ruoslahti, this volume). Massia \& Hubbell studied the adhesion of cells plated directly onto RGD peptides covalently attached to substrates. At very low densities, cells attach but do not spread. At higher densities, when the spacing between peptides reaches $\approx 440 \mathrm{~nm}$, cells spread but do not form FAs. However, at still higher densities of RGD peptides, with a spacing of $\approx 140 \mathrm{~nm}$ or less, spreading is accompanied by development of FAs (Massia \& Hubbell 1991). This requirement for a high density of integrin ligands suggests that the interacting integrins need to be clustered in order for FAs to form.

The development of FAs has been studied in cells adhering to cell-binding fragments of fibronectin that contain the RGD sequence. Whereas some investigators observed FAs on these domains of fibronectin (Singer et al 1987), others noted their failure to form (Beyth \& Culp 1984, Izzard et al 1986, Woods et al 1986) or that the FAs were small and abnormal (Streeter \& Rees 1987). Woods and coworkers found that assembly of FAs on the cell-binding fragment of fibronectin was stimulated by addition of a proteoglycan-binding domain of fibronectin (Woods et al 1986). Alternatively, the cells could be stimulated with phorbol esters to activate protein kinase C (PKC) (Woods \& Couchman 1992). The reason why FA formation on the cell-binding fragment of fibronectin requires this additional stimulation has been a puzzle, given that simple clustering of integrins with antibodies seems to mimic their formation. A possible explanation has been suggested by Hotchin \& Hall (1995) who have found that active Rho is required for FAs to form on intact fibronectin. In some situations, PKC stimulation has been reported to activate Rho (Hall 1994), which raises a question about the state of Rho in the experiments examining FA formation on fibronectin fragments. Was Rho relatively inactive in the cells that failed to form FAs on fibronectin fragments, and did it become activated by the proteoglycan-binding domains of fibronectin or by PKC stimulation? The role of Rho in clustering integrins into FAs is discussed below.

A transmembrane proteoglycan, syndecan 4, has been identified in the FAs of many different cell types adhering to various ECM proteins (Woods \& Couchman 1994). In serum-starved cells, syndecan 4 is absent from FAs but can be recruited by stimulating with serum or by activating PKC (Baciu \& Goetinck 1995). When cells are plated on fibronectin in the presence of serum, the localization of syndecan 4 to FAs increases with time and is more associated with mature FAs rather than with newly forming ones at the leading edge (Baciu $\&$ Goetinck 1995). The late recruitment of syndecan 4 to FAs suggests that it 
is not involved in the early signaling events associated with FA formation. It will be important to investigate the interactions of the syndecan cytoplasmic domain with structural and signaling components.

Dystroglycan (cranin, laminin-binding protein 120) (Smalheiser \& Schwartz 1987, Douville et al 1988, Ibraghimov-Beskrovnaya et al 1992, 1993, Gee et al 1993, Smalheiser \& Kim 1995) is a transmembrane receptor for laminin, unrelated to integrins that has been identified in the FAs of several cell types (Belkin \& Smalheiser 1996). It has been studied mainly in the context of skeletal muscle, where it binds dystrophin and is in a complex with several dystrophin-associated glycoproteins (Ibraghimov-Beskrovnaya et al 1992, Ervasti \& Campbell 1993a,b). However, dystroglycan is quite widely distributed (Smalheiser \& Schwartz 1987, Ibraghimov-Beskrovnaya et al 1993). It remains to be determined whether its presence in FAs is due to a direct association with some of the major structural proteins of FAs, such as talin, vinculin and $\alpha$-actinin, or whether it is associated indirectly via dystrophin or utrophin which, in turn, may be interacting with other components at these sites.

\section{Integrin Cytoplasmic Domains}

The cytoplasmic domains of integrins are critical for FA formation. Many of their structural features and interactions have been reviewed by Sastry \& Horwitz (1993). The role of the cytoplasmic domains in targeting $\beta_{1}$ and $\beta_{3}$ integrins to FAs has been studied using mutations, deletions, and chimeric constructs. Deletion of the $\beta_{1}$ cytoplasmic domain blocks FA localization of integrin heterodimers (Solowska et al 1989, Marcantonio et al 1990, Hayashi et al 1990), whereas chimeric constructs containing the $\beta_{1}$ cytoplasmic domain fused to unrelated receptors target to FAs (Geiger et al 1992b, LaFlamme et al 1992). Consistent with this, deletion of $\alpha$ cytoplasmic domains drives integrin heterodimers to FAs (Briesewitz et al 1993, Ylanne et al 1993). These results indicate that the $\beta$ subunit cytoplasmic domain is responsible for targeting an integrin to FAs, whereas the $\alpha$ subunit cytoplasmic sequence inhibits FA localization. Ligand binding relieves this inhibition (LaFlamme et al 1992). The relationship of the $\alpha$ and $\beta$ subunit cytoplasmic domains has not been fully resolved, but in the nonligand-bound state, the two cytoplasmic domains appear to be in a close proximity (Briesewitz et al 1995). Following ligand binding to the extracellular domain, a conformational change is transmitted to the cytoplasmic domains, allowing the $\beta$ cytoplasmic region to interact with focal adhesion components. Deletion of the $\alpha$ cytoplasmic domain or expression of the $\beta$ cytoplasmic domain on its own as a chimeric protein appears to mimic the ligand-bound state. 
A key question is whether ligand occupancy increases the affinity of interaction between integrins and cytoskeletal proteins. Miyamoto and colleagues compared the effects of integrin clustering with ligand occupancy (Miyamoto et al 1995a). Integrins were aggregated on the surface of cells using beads coated with non-inhibitory antibodies or with antibodies that block integrin function. Integrin clustering by non-inhibitory antibodies stimulates the colocalization of tensin and focal adhesion kinase (FAK), but not talin, vinculin, $\alpha$-actinin, or actin. Clustering integrins with inhibitory antibodies (which mimic ligand binding), or with non-inhibitory antibodies in the presence of soluble ligands, stimulates co-clustering of talin, vinculin, $\alpha$-actinin, and actin. These results argue that, while clustering alone will recruit some proteins, additional proteins are recruited in response to the combination of clustering and ligand occupancy. It may be that ligand occupancy is itself sufficient to induce this association between integrins and these cytoskeletal proteins, but this is difficult to resolve experimentally. Earlier work by this group, in which soluble ligands were seen to drive integrins into FAs formed by other integrins, strongly supports the idea that integrin occupancy is itself sufficient to induce cytoskeletal association with integrins (LaFlamme et al 1992).

Alternatively spliced cytoplasmic domains have been identified for both $\beta_{1}$ and $\beta_{3}$ integrin subunits. These differ in their ability to support FAs or target to these structures. In humans, four alternatively spliced isoforms of $\beta_{1}$ have been identified and are referred to as $\beta_{1 \mathrm{~A}}$ and $\beta_{1 \mathrm{~B}}$ (Balzac et al 1993, 1994), $\beta_{1 \mathrm{C}}$ (Languino \& Ruoslahti 1992), and $\beta_{1 \mathrm{D}}$ (van der Flier et al 1995, Zhidkova et al 1995, Belkin et al 1996). Recent genomic analysis of the mouse $\beta_{1}$ integrin gene located only the exons for $\beta_{1 \mathrm{~A}}$ and $\beta_{1 \mathrm{D}}$ (Baudoin et al 1996), which raises the possibility that the $\beta_{1 \mathrm{~B}}$ and $\beta_{1 \mathrm{C}}$ variants emerged late in the evolution of the $\beta_{1}$ integrin family. $\beta_{1 \mathrm{~A}}$ is the predominant and original isoform identified. In humans, $\beta_{1 \mathrm{~B}}$ and $\beta_{1 \mathrm{C}}$ appear to be relatively minor forms and are not found in FAs.

$\beta_{1 \mathrm{~B}}$ may be involved in regulation of adhesion and migration (Balzac et al 1993, 1994), whereas $\beta_{1 \mathrm{C}}$ exerts a negative effect on growth (Meredith et al 1995, Fornaro et al 1995) (discussed below). In contrast to the low levels of expression of $\beta_{1 \mathrm{~B}}$ and $\beta_{1 \mathrm{C}}$, the major $\beta_{1}$ integrin isoform in striated muscles is $\beta_{1 \mathrm{D}}$ (van der Flier et al 1995, Zhidkova et al 1995, Belkin et al 1996), which is found at all sites of actin filament-membrane attachment (Belkin et al 1996). Unlike the other isoforms, $\beta_{1 \mathrm{D}}$ and $\beta_{1 \mathrm{~A}}$ share significant sequence homology in their alternatively spliced regions. $\beta_{1 \mathrm{D}}$ is found in FAs, both in cultured myotubes and when transfected into nonmuscle cells (Belkin et al 1996). It has been speculated that $\beta_{1 \mathrm{D}}$ interacts not only with the structural proteins of FAs but also with the specialized cytoskeletal proteins that line the 
muscle sarcolemma (Belkin et al 1996). $\beta_{1}$ integrins appear to associate with the dystrophin-containing lattice in muscle development (Lakonishok et al 1992). The forces transmitted across the sarcolemma of striated muscles are much greater than those experienced by the plasma membranes of most other cells. These high forces may have generated the need for a unique integrin isoform to provide stronger attachments to the membrane.

\section{Cytoplasmic Proteins}

Recently, the number of proteins identified at the FA cytoplasmic face has expanded greatly (Table 1). So too have the number of interactions (Table 2). It has become difficult, if not impossible, to represent this complexity adequately (Figure 1). Several components, as well as interactions, have not been included. The diagram conveys neither the dynamic nature of many of the interactions nor the stoichiometry of the components. The relative abundance of FA constituents varies considerably; FAK, paxillin, tensin, zyxin, and many signaling components are minor compared with vinculin and talin. We are confident that more FA proteins will be discovered and that the complexity of interactions will increase further. Space limitations restrict our discussion to a few topics relevant to the assembly of these structures. More information about FA structural proteins is given elsewhere (Jockusch et al 1995).

One striking observation is that a large number of FA proteins bind actin. This large number hints at redundancy in the linkage of actin filaments to integrins (and possibly to other transmembrane components in FAs). Some of the actin-binding proteins may function at different stages in the life of a FA. It has been suggested, for example, that talin and vinculin may be involved in FA formation, whereas $\alpha$-actinin may be more important in maintaining or stabilizing microfilament attachment in mature FAs (DePasquale \& Izzard 1987, 1991, Pavalko \& Burridge 1991, Nuckolls et al 1992). Multiple linkages may also facilitate actin polymerization, permitting addition of actin monomers while

Table 2 Interactions between structural proteins in focal adhesions

Integrin Actin $\alpha$-actinin Fimbrin Profilin Radixin Talin Tensin VASP Vinculin Zyxin

\begin{tabular}{|c|c|c|c|c|c|c|c|c|c|c|c|}
\hline Integrin & - & - & 1 & - & - & - & 2 & - & - & - & - \\
\hline Actin & - & - & 3 & 4 & 5 & 6 & 7 & 8 & 9 & 10 & - \\
\hline$\alpha$-actinin & 1 & 4 & - & - & - & - & - & - & - & 11 & 12 \\
\hline VASP & - & 9 & - & - & 13 & - & - & - & - & - & 14 \\
\hline Vinculin & - & 10 & - & - & - & - & 15 & 16 & - & - & - \\
\hline
\end{tabular}

1. Otey et al 1990; 2. Horwitz et al 1986; 3. Burridge \& Feramisco 1980; 4. Bretscher 1981; 5. Lassing \& Lindberg $1985 ; 6$. Tsukita \& Hieda 1989; 7. Muguruma et al 1990, Kaufmann et al 1991; 8. Wilkins et al 1987, Lo et al 1994; 9 . Reinhard et al 1992; 10. Menkel et al 1994, Johnson \& Craig 1995a; 11. Belkin \& Koteliansky 1987, Wachsstock et al 1987; 12. Crawford et al 1992; 13. Reinhard et al 1995a; 14. Reinhard et al 1995b; 15. Burridge \& Mangeat 1984; 16. Wilkins et al 1987. 


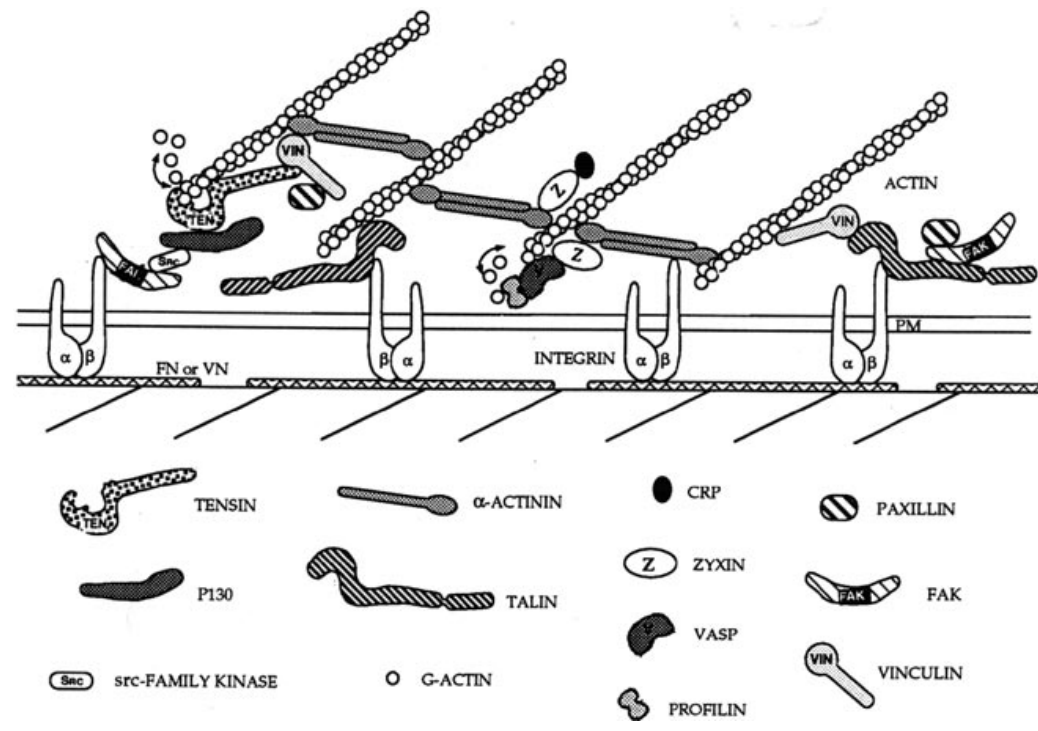

Figure 1 A focal adhesion. The model shows some of the interactions determined in vitro for proteins within focal adhesions formed on a surface coated with fibronectin (FN) or vitronectin $(\mathrm{VN})$. For the sake of clarity, so that linking proteins can be visualized, integrins are shown dispersed rather than clustered. They are linked to actin microfilaments via talin, vinculin and/or $\alpha$-actinin. Actin polymerization at these sites may involve either tensin or profilin, which interacts with VASP, a zyxin-binding protein. A few of the signaling components (FAK, paxillin, p130 ${ }^{\mathrm{cas}}$, src family kinases) have also been included; however, several FA proteins and many of the interactions have been omitted. It should be noted that the diagram misrepresents the stoichiometry of components in focal adhesions, i.e. some such as vinculin and talin appear to be many times more abundant than others, such as FAK, paxillin, tensin, and zyxin.

simultaneously maintaining attachment to the membrane. It is noteworthy that some FA proteins, including tensin and talin, have multiple actin-binding sites (Lo et al 1994; L Hemmings et al, manuscript submitted). These may also permit subunit addition while maintaining attachment, as has been suggested for insertin, a fragment of tensin (Weigt et al 1992, Ruhnau et al 1989). Additionally, multiple binding sites may cross-link actin filaments and thus stabilize attachments to the membrane.

The attachment of actin filaments to integrins in FAs remains poorly understood. Both talin and $\alpha$-actinin were shown to bind to integrins in vitro with relatively low affinity (Horwitz et al 1986, Otey et al 1990). A talin-binding site within the $\beta_{1 \mathrm{~A}}$ cytoplasmic domain corresponding to residues 780-789 was mapped using synthetic peptides (Tapley et al 1989). Work from this laboratory, 
however, indicates that sequences along most of the length of the cytoplasmic domain contribute to talin binding (K Simon, unpublished observations). In the case of $\alpha$-actinin, peptide-binding studies indicate that two regions in the cytoplasmic domain are involved, residues 768-778 and 785-794 (Otey et al 1993). It has been difficult to demonstrate that these interactions also occur in vivo. Working with neutrophils, Pavalko and coworkers demonstrated coimmunoprecipitation of $\alpha$-actinin and $\beta_{2}$ integrin (Pavalko \& LaRoche 1993). In an attempt to get at the in vivo associations of proteins with integrin cytoplasmic domains, Lewis \& Schwartz (1995) transfected full-length or truncated chicken $\beta_{1}$ integrins into mouse fibroblasts and examined the colocalization of proteins with these integrins after they had been clustered with antibody-coated beads. This provided a way to map regions of the $\beta_{1}$ cytoplasmic domain responsible for recruiting specific proteins. Deletion of the last 13 residues at the $\mathrm{C}$-terminus inhibits colocalization of talin, actin, and FAK with clustered integrins. Interestingly, $\alpha$-actinin continues to codistribute with integrins; this is blocked by deletion of an additional 15 residues. These experiments support the idea that talin binding to integrins is required for attachment of actin and that, on its own, $\alpha$-actinin is insufficient to recruit actin filaments to clustered integrins.

The localization of $\alpha$-actinin to FAs has been controversial. Although it is usually listed as a FA component, it is often not detected in FAs by immunofluorescence or electron microscopy even though it is prominent along the associated stress fibers (Zigmond et al 1979, Chen \& Singer 1982, Samuelsson et al 1993). However, when labeled $\alpha$-actinin is microinjected, it readily targets to FAs (Feramisco 1979, McKenna et al 1985, Sanger et al 1987). Pavalko and coworkers provided evidence that the inability to detect $\alpha$-actinin in FAs by immunofluorescence results from inaccessibility of the $\alpha$-actinin to antibodies (Pavalko et al 1995). FAs are dense structures and this may limit antibody accessibility.

Vinculin is one of the most abundant FA proteins, interacting with talin, $\alpha$-actinin, tensin, and paxillin. For many years, the reported interaction of vinculin with actin was controversial. The demonstration by Jockusch's group that a vinculin tail domain construct binds actin (Menkel et al 1994) was difficult to reconcile with the inability of several groups to find significant actin binding with intact vinculin (e.g. Evans et al 1984, Otto 1986). A breakthrough came with the discovery by Johnson \& Craig of an intramolecular, head-tail interaction within vinculin (Johnson \& Craig 1994). This interaction masks binding sites for both talin and actin in vinculin's head and tail domains, respectively (Johnson \& Craig 1994, 1995a). It seems likely that exposure of these sites is an important event in the assembly of FAs. It is notable that vinculin binds acidic phospholipids (Niggli et al 1986, Isenberg 1991), in particular PIP 2 
(Fukami et al 1994), and that the binding site for $\mathrm{PIP}_{2}$ is located in the hinge region between the head and tail domains (Johnson \& Craig 1995b). These observations prompted examination of the effects of lipids, specifically $\mathrm{PIP}_{2}$, on the conformation of vinculin. It was shown that the head-tail interaction of vinculin could be dissociated by acidic phospholipids and most effectively by $\mathrm{PIP}_{2}$ (Weekes et al 1996, Gilmore \& Burridge 1996). This exposed the binding sites for actin and talin, and a potential $\mathrm{PKC}$ phosphorylation site in the tail of vinculin. Vinculin immunoprecipitated from adherent cells contained $\mathrm{PIP}_{2}$, but not other phospholipids, consistent with $\mathrm{PIP}_{2}$ being the physiological effector of the conformational change (Gilmore \& Burridge 1996).

Significantly, $\mathrm{PIP}_{2}$ levels are elevated in response to adhesion in a Rhodependent manner (Chong et al 1994). These observations are discussed in more detail below in the context of FA assembly.

Zyxin is one of the less abundant proteins present in FAs and adherens junctions (Beckerle 1986). This 82-kDa protein, expressed most prominently in fibroblasts and muscle cells, contains a proline-rich stretch at the C-terminus, involved in binding $\alpha$-actinin (Crawford et al 1992), and three N-terminal LIM domains (Sadler et al 1992). LIM domains, each composed of two histidineand cysteine-rich zinc fingers, mediate specific protein-protein interactions (Schmeichel \& Beckerle 1994). They have been identified in a number of proteins, some of which are transcription factors, whereas others, such as the cysteine-rich proteins (CRP), are made up almost entirely of LIM domains. Zyxin does not contain an obvious nuclear targeting sequence, but truncation of the proline-rich $\mathrm{N}$-terminus induces nuclear localization of zyxin (Nix \& Beckerle 1995). In addition, a 44-amino acid sequence within the proline-rich region localizes zyxin to FAs. This raises the exciting possibility that zyxin shuttles between FAs and the nucleus in response to other factors interacting with this domain. The first LIM domain of zyxin binds to CRP, which is also localized in FAs (Sadler et al 1992, Crawford et al 1994). Expression of CRP proteins is tightly regulated during myogenesis and these proteins have been shown to potentiate muscle differentiation.

Another interesting interaction occurs between zyxin and VASP (M Reinhard et al 1995). VASP (vasodilator-stimulated phosphoprotein) was originally identified in platelets (Halbrugge \& Walter 1989) as a major substrate of the cAMP-dependent protein kinase (PKA) and the cGMP-dependent protein kinase (PKG), both of which are stimulated by agents that inhibit platelet activation. Subsequently, VASP was identified in fibroblast FAs and along stress fibers, as well as in membrane ruffles (Reinhard et al 1992, Haffner et al 1995). VASP contains a polyproline-rich sequence that binds profilin (M Reinhard et al 1995), thus indicating a possible function in the control of actin polymerization. 
This idea has received strong support from studies on the movement of Listeria monocytogenes. Listeria moves inside host cells by rapid polymerization of actin filaments at one pole of the bacterium (Pollard 1995). Both profilin and VASP have been identified at this site (Theriot et al 1994, Chakraborty et al 1995). VASP binds to the Listeria protein ActA (Pistor et al 1995), which is responsible for bacterial motility, and suggests that VASP provides a bridge between the bacterium and the microfilament system. Some sequence homology exists between ActA and zyxin, and these proteins even cross react immunologically (R Goldsteyn \& E Friederich personal communication). These observations suggest that zyxin, VASP, and profilin function as a complex, regulating the nucleation of actin polymerization at FAs and equivalent sites in cells. How important actin polymerization is in a stable FA is not clear. It is probably more important in the initial stages of FA development, during the assembly of stress fibers and FAs. This may explain why profilin is generally not detected in mature FAs (Buss et al 1992). An unanswered question concerns the role of VASP phosphorylation by the cyclic nucleotide-dependent protein kinases.

\section{CONTRACTILITY: INFLUENCE ON THE FORMATION OF STRESS FIBERS AND FOCAL ADHESIONS}

It had been suggested that stress fibers contract isometrically and that this isometric tension contributes to their assembly (Heath \& Dunn 1978, Burridge 1981). Numerous observations contributed to this hypothesis. For example, stress fibers contain many of the contractile proteins found in muscle, including actin and myosin II, and these are arranged in a sarcomeric type of organization (Weber \& Groesche-Stewart 1974, Lazarides \& Burridge 1975, Gordon 1978, Kreis \& Birchmeier 1980). Although this pattern is suggestive of a contractile function, stress fibers are rarely seen to shorten in living cells. However, they are potentially contractile, as revealed in permeabilized cells exposed to ATP (Isenberg et al 1976, Kreis \& Birchmeier 1980, Crowley \& Horwitz 1995). It was argued that shortening usually cannot occur because of the strong adhesion at FAs to a rigid substratum, which generates isometric tension. A visible manifestation of tension exerted on the underlying substrate is seen when cells are grown on flexible silicone rubber surfaces. Fibroblasts and other cells that have prominent stress fibers visibly wrinkle these substrates (Harris et al 1980). Detachment of cells from the rubber results in the rapid loss of wrinkles. Evidence that isometric tension can generate bundles of microfilaments comes from studies using cytoplasmic extracts of Physarum induced to contract under isotonic or isometric conditions (Fleischer \& Wohlfarth-Bottermann 1975). 
Isometric contraction generates dense arrays of microfilaments, reminiscent of stress fibers. These structures rapidly disassemble upon the release of tension, just as stress fibers disassemble when cells are detached from a substrate. In contrast, when the cytoplasmic extracts are stimulated to contract under isotonic conditions, shortening is not accompanied by the development of large bundles of microfilaments (Fleischer \& Wohlfarth-Bottermann 1975).

Much additional evidence supports the idea that isometric tension contributes to the formation of stress fibers. For example, fibroblasts contract collagen gels in which they are suspended. Free-floating gels may be contracted over several days to as little as $10 \%$ of their original size, and the fibroblasts in these gels lack stress fibers. If the gels are anchored, isometric tension is generated and the fibroblasts develop prominent stress fibers (Mochitate et al 1991, Tomasek et al 1992, Tomasek \& Haaksma 1991, Grinnell 1994, Halliday \& Tomasek 1995). Upon release of tension in anchored gels, there is a rapid contraction of the gel followed by disassembly of the stress fibers (Mochitate et al 1991, Tomasek et al 1992, Grinnell 1994). Application of tension to cells in culture also stimulates the formation of stress fibers (Franke et al 1984). When tension is applied to a localized region of the cell surface, a bundle of actin filaments is induced immediately subjacent to the site of applied tension (Kolega 1986).

Danowski demonstrated that when contractility is stimulated in fibroblasts by microtubule depolymerization, formation of stress fibers is induced (Danowski 1989). Under these conditions, FAs are also stimulated to form (B Geiger \& A Bershadsky, personal communication; M Chrzanowska-Wodnicka, unpublished observations). How microtubule depolymerization stimulates contractility has not been established. One set of models has invoked "tensegrity" theories, in which microfilaments are viewed as tension-generating elements and microtubules as compression-resisting struts (Ingber 1993, Buxbaum \& Heidemann 1988). The collapse of the compression-resisting elements, the microtubules, should lead to increased contractility. However, an alternative interpretation has been suggested by Kolodney \& Elson, who have demonstrated enhanced myosin light chain (MLC) phosphorylation in response to microtubule depolymerization. This suggests that microtubule depolymerization directly activates actomyosin contractility, rather than simply removing an opposing structural element (Kolodney \& Elson 1995).

Agents that inhibit contractility promote stress fiber and FA disassembly. For example, stress fibers are disrupted by microinjection of antibodies that bind to the myosin rod domain and inhibit myosin filament assembly (Honer et al 1988). Butanedione monoxime (BDM) inhibits myosin ATPase activity (Higuchi \& Takemori 1989, McKillop et al 1994, Cramer \& Mitchison 1995), decreases fibroblast contractility, and leads to the reversible disassembly of 
both stress fibers and FAs (Chrzanowska-Wodnicka \& Burridge 1996). It has been long known that high cAMP levels disrupt stress fibers in many cell types. Pursuing the basis for this, Lamb and coworkers related the effects of high cAMP to decreased MLC phosphorylation (Lamb et al 1988). Elevated PKA activity disrupts stress fibers and leads to phosphorylation of the MLC kinase (MLCK), which has been correlated with decreased activity in vitro. MLCK is a key protein regulating nonmuscle actin-myosin interaction and contractility (see below). Further evidence for a role for MLCK in stress fiber stability was obtained by microinjection of antibodies against the MLCK into cells. The antibodies immunoprecipitated MLCK and led to the disassembly of stress fibers (Lamb et al 1988). The FAs were not examined in these experiments, but in a separate study, elevation of cAMP in the same cell type disrupted FAs (Turner et al 1989). Pharmacological agents that inhibit MLCK also inhibit contractility and lead to stress fiber and FA disassembly (Volberg et al 1994, Chrzanowska-Wodnicka \& Burridge 1996). MLC phosphorylation can also be modulated by protein phosphatases. Elevating the level of protein phosphatase 1 (PP1) in fibroblasts by microinjection decreases MLC phosphorylation, which leads to a rapid loss of stress fibers (Fernandez et al 1990).

Taken together, this large body of evidence supports the idea that isometric tension induced by contractility drives the formation of stress fibers and FAs. Conversely, these structures disassemble when contractility is inhibited or tension is released. Some agents that stimulate formation or disassembly of FAs may exert their primary effects on contractility. For this reason, and because nonmuscle contractility can be modulated in many different ways, we discuss the regulation of contractility in the next section.

\section{Regulation of Contractility}

Much of what is known about the regulation of vertebrate nonmuscle contractility is derived from work on vertebrate smooth muscle. Many, but not all, of the regulatory components are present in both systems. In smooth muscle and nonmuscle cells, the dominant regulatory system involves phosphorylation of the myosin regulatory light chains ( $20 \mathrm{kDa}$ ) by a MLCK (Figure 2). MLCK phosphorylates both Ser-19 and Thr-18 (Sellers 1991, Tan et al 1992). Ser-19 is the major site of phosphorylation induced by agonists that stimulate light chain phosphorylation. Thr- 18 is phosphorylated at a slower rate but becomes phosphorylated under conditions of maximal stimulation. The phosphorylation of the regulatory light chain increases the actin-activated ATPase activity of both smooth and nonmuscle myosin II (Adelstein \& Conti 1975) and is required for myosin-driven actin filament movement in in vitro motility assays (Sellers 1991, Tan et al 1992). This regulation of myosin motor function may be the primary role of this light chain phosphorylation. 


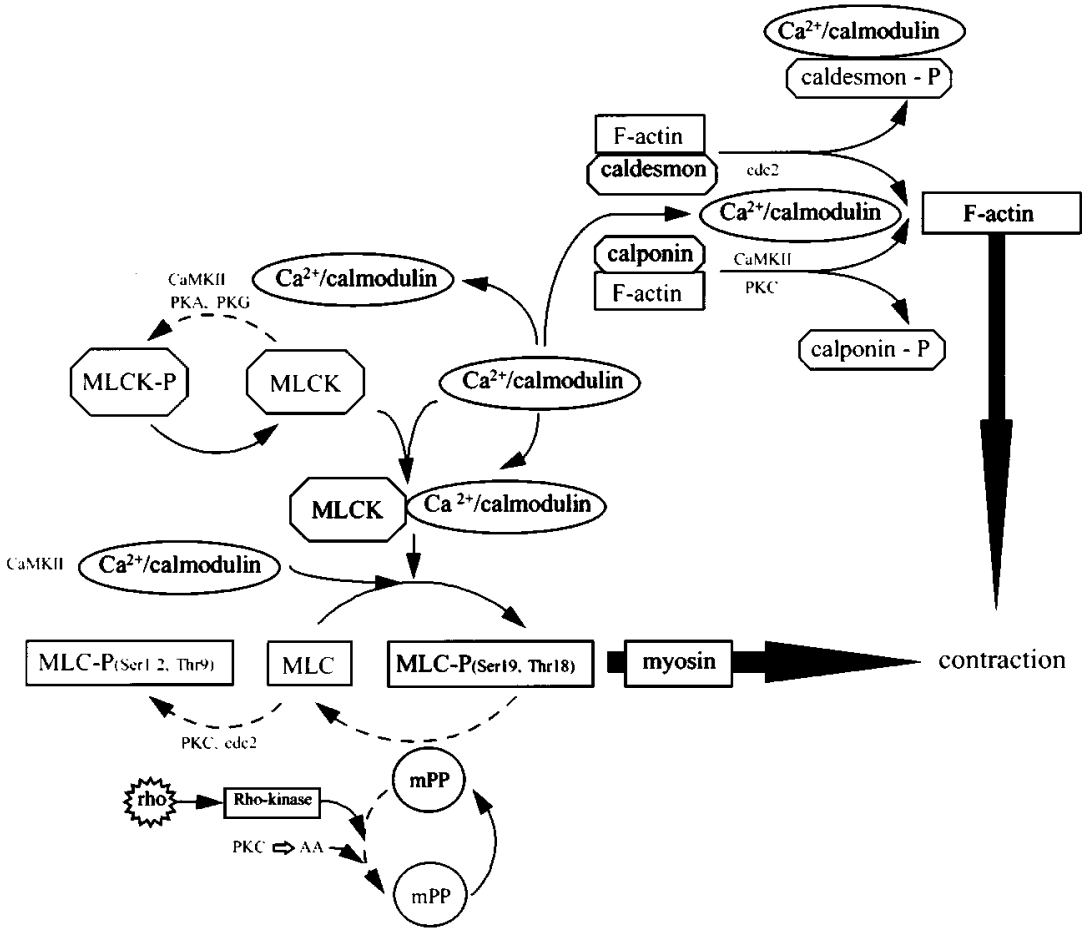

Figure 2 Regulation of contractility in smooth muscle and nonmuscle cells. The interaction of myosin with actin is regulated by phosphorylation of the regulatory myosin light chains (MLC) as well as by the actin-binding proteins, caldesmon and calponin. Active proteins are shaded, inactive are blank. MLC phosphorylation on Ser-19 and Thr-18 is catalyzed by the MLCK, which is activated by binding $\mathrm{Ca}^{2+} /$ calmodulin. The same sites on MLCs can also be phosphorylated by CaM kinase II (CaMKII). MLCK is inhibited by phosphorylation by PKA, PKG, or CaM kinase II. MLC dephosphorylation occurs by a myosin phosphatase (mPP), which is inhibited in smooth muscle by activated Rho-stimulates Rho-kinase, which phosphorylates mPP, thereby inhibiting it activity (Kimura et al 1996). The myosin phosphatase is also inhibited by arachidonic acid, which may be generated by activation of PKC. Inhibitory phosphorylation of MLCs occurs primarily on Ser-1 and Ser-2, but also on Thr-9 in vitro, and is catalyzed by PKC and the mitotic kinase $\mathrm{p} 34^{\mathrm{cdc} 2}$ (cdc2). The actin-binding proteins, caldesmon and calponin, inhibit the interaction of myosin with actin in the absence of $\mathrm{Ca}^{2+}$. In the presence of $\mathrm{Ca}^{2+}$, the inhibition is relieved either by phosphorylation of caldesmon or calponin, or by binding $\mathrm{Ca}^{2+} /$ calmodulin. Phosphorylation of caldesmon by $\mathrm{p} 34^{\text {cdc2 }}$ also releases caldesmon from actin. 
Regulatory light chain phosphorylation also induces a conformational change in the myosin monomer (Craig et al 1983, Citi \& Kendrick-Jones 1986, Ikebe $\&$ Reardon 1990) that might be involved in control of thick filament assembly. Nonmuscle myosin II can exist in two conformational states. In the first, the myosin rod is folded back on itself and interacts with the myosin heads. The second conformation is elongated, resembling the classical conformation of isolated skeletal muscle myosin (Citi \& Kendrick-Jones 1986). In the folded conformation, myosin cannot assemble into filaments. The equilibrium between the two conformational states is shifted by phosphorylation of Ser-19. This favors the extended conformation and promotes assembly of myosin filaments. Phosphorylation of Thr-18 stabilizes the extended conformation and may also enhance filament formation (Ikebe 1989, Ikebe et al 1988). In lower organisms, such as Dictyostelium, phosphorylation of the heavy chains inhibits myosin filament assembly (Tan et al 1992). In vertebrate smooth and nonmuscle cells, heavy chain phosphorylation also occurs. Whether this phosphorylation regulates myosin filament assembly has not been determined, although it seems a likely possibility.

The MLCK from smooth muscle and nonmuscle cells is regulated by $\mathrm{Ca}^{2+}$ / calmodulin binding. In the resting state, in the absence of intracellular calcium, an auto-inhibitory domain blocks the kinase domain within MLCK (Tan et al 1992). Elevation of intracellular calcium results in calmodulin binding to MLCK. This causes a conformational shift of the auto-inhibitory domain, which activates the kinase. The interaction of MLCK with calmodulin is additionally regulated by phosphorylation. PKA, PKG, and CaM kinase II can all phosphorylate MLCK at a site that decreases its affinity for $\mathrm{Ca}^{2+} /$ calmodulin, thus inhibiting MLCK activity (Nishikawa et al 1984, Tansey et al 1994). A novel isoform of MLCK (embryonic MLCK) has recently been identified in nonmuscle cells (Gallagher et al 1995). This is the predominant or only MLCK expressed by some cells, whereas elsewhere this MLCK is coexpressed with the smooth muscle isoform. This embryonic MLCK is regulated by calcium, but little else is known about its regulation. The MLCK from Dictyostelium does not have a $\mathrm{Ca}^{2+} /$ calmodulin binding site, and its regulation remains to be elucidated (Tan et al 1992).

Dephosphorylation of MLCs counteracts the effect of their phosphorylation and provides a target for regulating myosin/actin interaction. The predominant myosin phosphatase (mPP), an isoform of PP1, consists of three subunits: a 37$\mathrm{kDa}$ catalytic subunit, a 130-kDa subunit that targets the phosphatase to myosin, and a 20-kDa subunit (Alessi et al 1992, Shimizu et al 1994, Shirazi et al 1994). Dissociation of the catalytic subunit from the other components decreases its activity and is one mechanism by which agonists such as arachidonic acid may 
stimulate contractility (Gong et al 1992, Somlyo \& Somlyo 1994). Another mechanism for regulating mPP activity is by phosphorylation of the $130-\mathrm{kDa}$ myosin-binding subunit (Trinkle-Mulcahy et al 1995, Ichikawa et al 1996). In permeabilized smooth muscle cells, ATP- $\gamma$-S promoted contractility and elevated MLC phosphorylation at low calcium concentrations. This was due to decreased $\mathrm{mPP}$ activity and correlated with thiophosphorylation of the $130-\mathrm{kDa}$ subunit of mPP (Trinkle-Mulcahy et al 1995). Studying purified mPP, Ichikawa and coworkers (1996) demonstrated the presence of a kinase associated with the phosphatase. This kinase phosphorylated the 130-kDa subunit, decreasing phosphatase activity. Kaibuchi and colleagues have shown that activated Rho stimulates Rho-kinase to phosphorylate the 130-kDa subunit of mPP, thereby inhibiting mPP activity (Kimura et al 1996) (see below).

The regulatory light chains of smooth and nonmuscle myosins are substrates for other kinases in addition to MLCK. CaM kinase II can phosphorylate Ser19, the same site that is phosphorylated by MLCK (Tan et al 1992). However, because the affinity of CaM kinase II for $\mathrm{Ca}^{2+} /$ calmodulin is 100 -fold less than that of MLCK, it may not be relevant under most conditions. PKC phosphorylates the regulatory light chain on three sites in vitro, Ser-1, Ser-2, and Thr-9, and the two serines have also been observed to be phosphorylated in vivo (Tan et al 1992). Phosphorylation at these sites decreases the actin-activated ATPase of myosin previously phosphorylated by MLCK and impairs myosin filament stability (reviewed in Tan et al 1992). The action of PKC is essentially antagonistic to MLCK with regard to myosin activity and contractility. p34 ${ }^{\text {cdc2 }}$ also phosphorylates the regulatory light chains on Ser-1 and Ser-2 (Satterwhite et al 1992). The phosphorylation on Ser-1 and Ser-2 is high in mitotically arrested cells and remains high during mitosis until anaphase, when the contractile ring begins to develop. At this point there is decreased phosphorylation on Ser-1 and Ser-2 and increased phosphorylation on Ser-19 (Satterwhite et al 1992, Yamakita et al 1994).

These results have led to the hypothesis that light chain phosphorylation by p3 $4^{\text {cdc2 }}$ inhibits contractility during mitosis until the onset of cytokinesis, at which point contractility is important for the contractile ring and the development of the cleavage furrow. The loss of stress fibers and FAs in mitotic cells is striking and correlates well with decreased contractility induced by $\mathrm{p} 34^{\mathrm{cdc} 2}$. This also supports the idea that the presence of stress fibers and FAs depends on contractility and that inhibition of contractility leads to disassembly of these structures.

Although light chain phosphorylation is a major regulatory target for smooth muscle and nonmuscle contractility, other regulatory proteins have also been identified (Figure 2). Caldesmon and calponin, two calcium-regulated proteins 
found on smooth muscle thin filaments, inhibit the actin-activated myosin ATPase in vitro in the absence of calcium. Nonmuscle cells contain a lower molecular weight isoform of caldesmon, which lacks a central domain of the smooth muscle caldesmon. Although the nonmuscle form of caldesmon is significantly smaller, its properties appear to be similar to the smooth muscle form. Caldesmons bind both actin and myosin (Matsumura \& Yamashiro 1993). Together with tropomyosin, caldesmon binding to actin filaments increases their stability and resistance to severing by gelsolin in vitro (Ishikawa et al 1989a,b). In reconstituted systems, caldesmon has been shown to inhibit tropomyosinstimulated, actin-activated myosin ATPase (Yamashiro et al 1995). This effect of caldesmon results from its binding to actin and is lost in the presence of $\mathrm{Ca}^{2+}$ and calmodulin, which release caldesmon from the actin-myosin complex and permit actin-myosin interaction. Caldesmon is phosphorylated by several serine/threonine kinases in vitro (Matsumura \& Yamashiro 1993), and the phosphorylation of caldesmon has been reported to affect its interactions with the actomyosin system. In particular, phosphorylation of caldesmon by p3 $4^{\mathrm{cdc} 2}$ may be one of the events regulating reorganization of the actin cytoskeleton during mitosis (Yamashiro et al 1990, 1991). Phosphorylated caldesmon dissociates from microfilaments, which may promote microfilament severing by gelsolin, thereby contributing to the mitotic disassembly of stress fibers.

Calponin is a 35-kDa protein found primarily in smooth muscle, although it is reported also to be also in some nonmuscle cells (Takeuchi et al 1991). It regulates myosin ATPase activity in a phosphorylation-dependent fashion. When not phosphorylated, it binds to actin and inhibits the Mg ATPase activity of myosin in vitro. Phosphorylation of calponin by $\mathrm{PKC}$ or the $\mathrm{Ca}^{2+}$ /calmodulindependent protein kinase II relieves this inhibition (Winder \& Walsh 1990). Calponin phosphorylation increases in parallel with MLC phosphorylation as smooth muscle is induced to contract by activating with carbachol or with okadaic acid, which inhibits the intrinsic phosphatases, consistent with a role of calponin phosphorylation in regulating the contractility of smooth muscle (Winder \& Walsh 1990).

\section{RHO}

A major regulator of FAs and stress fibers is the small GTP-binding protein Rho (Hall 1994, Takai et al 1995), which is a member of the ras superfamily of proteins. In mammalian cells, it belongs to a subfamily that consists of Rho, rac, cdc42, TC10, and rhoG. Each of these proteins has several closely related isoforms (Hall 1994). In addition to other functions, these Rho-related proteins regulate the organization of the actin cytoskeleton. Whereas Rho regulates FAs and stress fibers (Ridley \& Hall 1992), Rac promotes membrane 
ruffling (lamellipodia) (Ridley et al 1992), and cdc42 promotes the extension of microspikes (filopodia) (Nobes \& Hall 1995). Here we concentrate on the effects and mechanism of Rho (Table 3 ).

The functions of Rho have been studied using two powerful tools: The first is the Clostridium botulinum C3 exotransferase (C3), which ADP-ribosylates and inactivates Rho (Narumiya et al 1988, Sekine et al 1989, Aktories \& Hall 1989). The second is a recombinant, constitutively activated Rho, which is generated by mutating glycine-14 within rho's effector domain to valine (Val-14rho). This mutation is equivalent to the Val-12 activating mutation in ras, which decreases GTPase activity. The disruption of stress fibers by the $\mathrm{C} 3$ exotransferase first indicated a function for Rho in the regulation of actin filaments (Chardin et al 1989). This work was extended by Paterson and colleagues who introduced constitutively activated Rho into cells, stimulating their development of a contracted morphology (Paterson et al 1990). Microinjection of activated Rho into quiescent mouse fibroblasts lacking stress fibers and FAs rapidly induces these structures to form (Ridley \& Hall 1992). The quiescent fibroblast system has

Table 3 Effects of Rho

Cell type References

Cytoskeletal effects

Regulation of cell morphology

Vero cells

Chardin et al 1989

Induction of stress fibers

Swiss 3 T3 fibroblasts

Paterson et al 1990

Swiss 3 T3 fibroblasts,

Ridley \& Hall 1992 mast cells,

MDCK epithelia

Induction of actin polymerization

Regulation of cell motility

Mast cells

Neutrophils, mouse 308R

Swiss 3T3 cells

Inhibition of SF/HGF-induced motility

Cell division,

MDCK epithelia

cleavage furrow formation

Enhancement of contractility

$\mathrm{Ca}^{+2}$ sensitization

Neurite retraction and cell rounding

MLC phosphorylation

Xenopus embryos, sand dollar eggs

Smooth muscle

Smooth muscle

Neurons

Smooth muscle

Price et al 1995

Ridley et al 1995

Norman et al 1994

Takaishi et al 1993

Takaishi et al 1994

Stasia et al 1991

Ridley et al 1995

Kishi et al 1993

Mabuchi et al 1993

Hirata et al 1992

Kokubu et al 1995

Jalink et al 1994

Noda et al 1995

Regulation of integrins

Inhibition of integrin-dependent

adhesion to fibronectin

Integrin-dependent aggregation

Chemoattractant-induced adhesion

Monocytes

Platelets,

B lymphocytes

Lymphocytes
Aepfelbacher 1995

Morii et al 1992

Tominaga et al 1993

Laudanna et al 1996 
been employed by Rozengurt and colleagues to study the actions of growth factors and neuropeptides. In addition to inducing the reformation of stress fibers and FAs, these agents stimulate the tyrosine phosphorylation of several FA proteins, including FAK, paxillin, and p130 cas (Zachary et al 1992, 1993, Kumagai et al 1993, Seckl \& Rozengurt 1993, Seufferlein \& Rozengurt 1994, 1995). Several of these agents (LPA, bombesin, endothelin, thrombin) mediate their effects via Rho (Ridley \& Hall 1992, Jalink et al 1994, Rankin et al 1994). These factors act on receptors that are coupled to heterotrimeric $\mathrm{G}$ proteins, including $\mathrm{G}_{\alpha 12}$ and $\mathrm{G}_{\alpha 13}$ (Buhl et al 1995). The pathway(s) from these to Rho have not been elucidated, although there is evidence for a tyrosine kinase (PTK) upstream of Rho (Nobes et al 1995). Ultimately, these agents must converge to promote the active form of Rho with GTP bound.

Like other G proteins, Rho is active when it has GTP bound. The intrinsic GTPase activity of Rho hydrolyzes the bound GTP, rendering Rho inactive. The cycling between the GTP-bound and GDP-bound forms is directly regulated by several proteins. For the ras family of proteins, the low intrinsic rate of GTP hydrolysis is enhanced by GTPase-activating proteins (GAPs), whereas the exchange of GDP for GTP is enhanced by guanine nucleotide exchange factors (GEFs). Guanine nucleotide dissociation inhibitors (GDIs) slow the rate of GDP dissociation and thereby lock the G protein into the inactive state (Hall 1994). GEFs activate G proteins, whereas GAPs will turn them off, and GDIs maintain them in the inactive state. Several GAPs for Rho have been identified (Ridley 1995). The first, rhoGAP, has a higher activity for cdc42 (Ridley et al 1993). A second GAP for Rho, p190 (Lancaster et al 1994), prevents the formation of stress fibers and FAs when microinjected into cells (Ridley et al 1993). Recently, another form of p190 was discovered (Burbelo et al 1995). An unconventional myosin has been described with rhoGAP activity in the tail domain (J Reinhard et al 1995). One GEF for Rho is the product of the $\mathrm{Dbl}$ oncogene. The region of Dbl responsible for GEF activity (Dbl homology domain) has been identified in several other proteins including Vav, Ect2, Lbc, Ost, Tim, and Tiam (Ridley 1995), some of which may have GEF activity for Rho or other Rho family members. A rhoGDI has been identified that acts on Rho, Rac, and cdc42. Introduction of rhoGDI into cells inhibits both Rho- and rac-dependent reorganization of actin (Nishiyama et al 1994). The regulation of Rho and related proteins is clearly complex. Adding to this complexity is evidence that various members of the ras superfamily may interact via their GAPs, GEFs, and GDIs. For example, p120 RasGAP interacts with p190 RhoGAP (Settleman et al 1992). Much remains to be learned about the interplay of ras family regulatory proteins. 


\section{Downstream Targets of Rho}

Several potential targets for Rho have been identified. Cell adhesion regulates the level of $\mathrm{PIP}_{2}$. Cells put into suspension demonstrate decreased levels of $\mathrm{PIP}_{2}$. This limits the response of suspended cells to growth factors that exert their growth stimulating effects via $\mathrm{PIP}_{2}$ hydrolysis (McNamee et al 1993). $\mathrm{PIP}_{2}$ synthesis from its precursor PIP, catalyzed by PIP 5-kinase, is stimulated by activated Rho (Chong et al 1994), and recently an interaction between Rho and one PIP 5-kinase isoform has been identified (Ren et al 1996, Kimura et al 1996). $\mathrm{PIP}_{2}$ acts on several cytoskeletal proteins, promoting actin polymerization and enhancing FA formation (see below).

By analogy with ras, which activates the raf/MEK/MAP kinase pathway (Vojtek \& Cooper 1995), it was expected that Rho would initiate a kinase cascade. The Rho family members, Rac and cdc42, have been shown to activate kinase pathways that parallel the ras/MAP kinase pathway (Coso et al 1995, Minden et al 1995). In addition, Rho was shown to activate one of the endpoints of these Rac and cdc42 pathways (Hill et al 1995). During the past year, two distinct serine/threonine protein kinases that interact with Rho have been identified by several groups. The first was detected initially using GTP-Rho to screen a rat brain expression library (Leung et al 1995). The sequence of this Rho-binding kinase $(\mathrm{ROK} \alpha)$ appears to be the truncated form of a bovine brain kinase (Rho-kinase) retained on a GST-Rho affinity column (Matsui et al 1996). A similar kinase was isolated from human platelets using labeled GTP-Rho in ligand overlay assays, cloned and given the name p160 ${ }^{\mathrm{ROCK}}$ (Rho-associated, coiled-coiled-containing protein kinase) (Ishizaki et al 1996). P160 ${ }^{\mathrm{ROCK}}$ has significant sequence homology with $\mathrm{ROK} \alpha /$ Rho-kinase with the differences possibly reflecting tissue isoforms or species variation. This family of kinases shares homology particularly in its kinase domain with the myotonic dystrophy kinase. Experiments with the purified Rho-kinase indicate that it has little if any kinase activity for many cytoskeletal proteins, with the striking exception of the myosin-binding subunit of the myosin phosphatase (Matsui et al 1996, Kimura et al 1996). As discussed below, this suggests an important link between Rho pathways and contractility, because phosphorylation of this subunit of the myosin phosphatase inhibits the phosphatase activity (Trinkle-Mulcahy et al 1995, Ichikawa et al 1996, Kimura et al 1996). A different serine/threonine protein kinase, PKN, that interacts with Rho was also identified by two of the above groups (Watanabe et al 1996, Amano et al 1996). In addition, the yeast two-hybrid system was used to identify rhophilin, a protein sharing homology with PKN but lacking kinase activity (Watanabe et al 1995). The discovery of these Rho-stimulated serine/threonine kinases is exciting. Each may be the first step in distinct kinase cascades initiated by activated Rho. 
Rho may also regulate the affinity of certain integrins for their ligands. Some integrins require activation for binding to their ligands, a phenomenon known as inside-out signaling (for details, see Ginsberg et al 1993, Schwartz et al 1995). The platelet integrin $\alpha_{\mathrm{IIb}} \beta_{3}$ is held in an inactive conformation until platelets are stimulated by thrombin or other agents that trigger blood clot formation. Following platelet stimulation, activation of $\alpha_{\mathrm{IIb}} \beta_{3}$ is a late event leading to platelet aggregation. This is blocked by the $\mathrm{C} 3$ exotransferase (Morii et al 1992). The inhibition of platelet aggregation by C3 may reflect rho's action on the cytoskeleton, or on the activation of $\alpha_{\mathrm{II}} \beta_{3}$ because both are involved in platelet aggregation. Members of the leukocyte $\beta_{2}$ integrin family similarly require activation. Cell adhesion by $\alpha_{\mathrm{L}} \beta_{2}$ is blocked by C3 (Tominaga et al 1993). This inhibition differs from the effects of cytochalasin, indicating that the action of Rho cannot be accounted for simply by its effects on the cytoskeleton and suggesting direct effects on integrin activation. The use of C3 has implicated Rho in the activation of $\beta_{1}$ and $\beta_{2}$ integrins in response to chemoattractants (Laudanna et al 1996). The original observations that C3 causes rounding up of cells are also consistent with $\mathrm{C} 3$ decreasing adhesion by blocking an effect of Rho on integrins (Chardin et al 1989, Paterson et al 1990). Together, these results suggest that Rho may activate integrins, increasing their interaction with ECM ligands, although the mechanism is far from clear.

\section{Rho and Contractility}

Rho is a potent stimulator of stress fibers and focal adhesions. As discussed earlier, contractility and isometric tension also contribute to stress fiber and FA formation. This leads to the question: Does Rho induce formation of these structures by stimulating contractility? Several lines of evidence support this idea. Many of the agents that activate Rho, such as LPA, endothelin, bombesin, and thrombin, are vasoconstrictors, which stimulate smooth muscle contraction. Direct evidence for an effect of Rho on contraction comes from studies with permeabilized smooth muscle. In this system, introduction of activated Rho enhances contractility at given calcium concentrations and lowers the calcium requirement for contractility (Hirata et al 1992). Rho has been implicated in several other contractile events (Table 3). For example, microinjection of C3 inhibits the development of the contractile ring, a transient bundle of microfilaments responsible for generating the cleavage furrow and cytokinesis (Mabuchi et al 1993, Kishi et al 1993). Some Rho-activating agents appear to stimulate contraction of cells other than smooth muscle. For example, thrombin stimulates neurite retraction (Jalink \& Moolenaar 1992, Suidan et al 1992) and induces contraction of fibroblasts and endothelial cells (Giuliano \& Taylor 1990, Goeckeler \& Wysolmerski 1995). LPA stimulates contraction of chicken embryo fibroblasts and human endothelial cells (Kolodney \& Elson 1993), as well 
as neurite retraction (Jalink et al 1994). The contractions induced by LPA and thrombin are Rho-mediated based on their inhibition by C3 (Jalink et al 1994). Induction of stress fibers and FAs by LPA treatment of quiescent Balb/c 3T3 cells is accompanied by an increase in contractility (Chrzanowska-Wodnicka \& Burridge 1996). Several agents that inhibit actin-myosin interaction block the LPA-induced formation of stress fibers and FAs, and inhibit the LPA-stimulated tyrosine phosphorylation of FA components. These inhibitors also block FA and stress fiber assembly induced by microinjected Rho, indicating that contractility is downstream of Rho in the LPA pathway (Chrzanowska-Wodnicka \& Burridge 1996).

How might Rho stimulate contractility? LPA and thrombin stimulate MLC phosphorylation (Kolodney \& Elson 1993, Goeckeler \& Wysolmerski 1995, Chrzanowska-Wodnicka \& Burridge 1996). This increase in MLC phosphorylation appears to precede the appearance of stress fibers and FAs, which suggests that it is an early event in the assembly of these structures rather than a consequence of their formation (Chrzanowska-Wodnicka \& Burridge 1996). MLC phosphorylation could result from stimulation of MLCK or inhibition of the MLC phosphatase. Several studies on smooth muscle point to an inhibition of phosphatase activity by Rho. In smooth muscle, it has been known for some time that excitatory agonists stimulate higher MLC phosphorylation than that induced by $\mathrm{KCl}$ depolarization, suggesting that these agonists potentiate phosphorylation not only by elevating intracellular calcium, but also by an additional mechanism (Somlyo \& Somlyo 1994). Using permeabilized smooth muscle preparations, MLC phosphorylation and contractility are enhanced at fixed calcium concentrations by GTP $\gamma \mathrm{S}$, which suggests the involvement of a $\mathrm{G}$ protein (Kitazawa et al 1991). In this system, GTP $\gamma \mathrm{S}$ inhibits MLC dephosphorylation, consistent with inhibition of a phosphatase (Kitazawa et al 1991). C3 blocks the GTP $\gamma$ S-enhanced phosphorylation of MLCs, implicating Rho in this process (Noda et al 1995). In addition, C3 promotes the dephosphorylation of MLCs in permeabilized smooth muscle, further suggesting that Rho inhibits the MLC phosphatase (Noda et al 1995).

Two recent observations suggest a pathway by which Rho may inactivate the MLC phosphatase (mPP). First, there is the discovery that phosphorylation of the 130-kDa-subunit of mPP inhibits its activity (Trinkle-Mulcahy et al 1995, Ichikawa et al 1996, Kimura et al 1996). Second, there is the identification of the Rho-stimulated serine/threonine kinases (Leung et al 1995, Amano et al 1996, Watanabe et al 1996, Ishizaki et al 1996, Matsui et al 1996). One of these, Rho-kinase, phosphorylates the 130-kDa subunit of mPP in vitro (Matsui et al 1996, Kimura et al 1996). It will be important to establish whether Rho-kinase alone or a Rho-activated kinase cascade is involved in the inactivation of $\mathrm{mPP}$ in 
vivo. Potential pathways by which Rho may regulate MLC phosphorylation and other cytoskeletal events such as actin polymerization are indicated in Figure 3.

\section{A MODEL FOR FOCAL ADHESION ASSEMBLY}

Based on the observations discussed above, we have proposed a model for how contractility can promote the assembly of FAs (Figure 4) (ChrzanowskaWodnicka \& Burridge 1996). In this model, cells in suspension have integrins dispersed over the cell surface $(A)$. Clustering the integrins with antibodies $(B)$ coclusters FAK and stimulates tyrosine phosphorylation. In the absence of ligand binding, the integrins are not associated with actin filaments. Cells adhering to ECM via integrins are shown in panels $C$ and $D$. In $C$, the cells are quiescent. The integrins mediating adhesion to the underlying ECM are distributed over the ventral surface and are not clustered into FAs. However, because the integrins are bound to their ECM ligands, they are coupled physically to actin microfilaments via proteins such as talin or $\alpha$-actinin. The actin filaments associated with these integrins are under little or no tension, because the myosin II is in its inactive conformation. In $D$, the cells have been stimulated to contract by agents that activate Rho. Rho activation leads to MLC phosphorylation. This turns on myosin function and also possibly induces a conformational change in the myosin, promoting myosin filament assembly. The resulting force generation will align the actin filaments. Alignment will also be promoted by the bundling action of the myosin filaments, which are very effective at cross-linking F-actin. The tension generated will be transmitted to the integrins in the membrane, leading to their aggregation. This clustering of integrins is a cornerstone in the assembly of FAs. Certainly, clustering of integrins from the outside, in combination with ligand occupancy, induces colocalization of many FA proteins (Miyamoto et al 1995a,b). In earlier models, it was assumed that simply plating cells on ECM proteins leads to the clustering of integrins in FAs. However, this does not occur if Rho is inactive (Hotchin $\&$ Hall 1995), which implies that the clustering is driven in some way from the inside rather than from interactions with the ECM on the outside. We have noted that integrins mediating adhesion will aggregate into FAs when contractility is stimulated and, conversely, will disperse from FAs when contractility is inhibited (Chrzanowska-Wodnicka \& Burridge 1996). The generally low affinity of integrins for their ECM ligands (Hynes 1992) should result in relatively rapid rates of dissociation. These will permit remodeling of integrin-ECM interactions in response to tension.

In the formation of FAs induced by activated Rho, we envisage a cooperativity between the clustering of integrins driven by contractility and the effects of elevated PIP $_{2}$ (Figure 3). Activated Rho stimulates PIP 5-kinase (Chong 


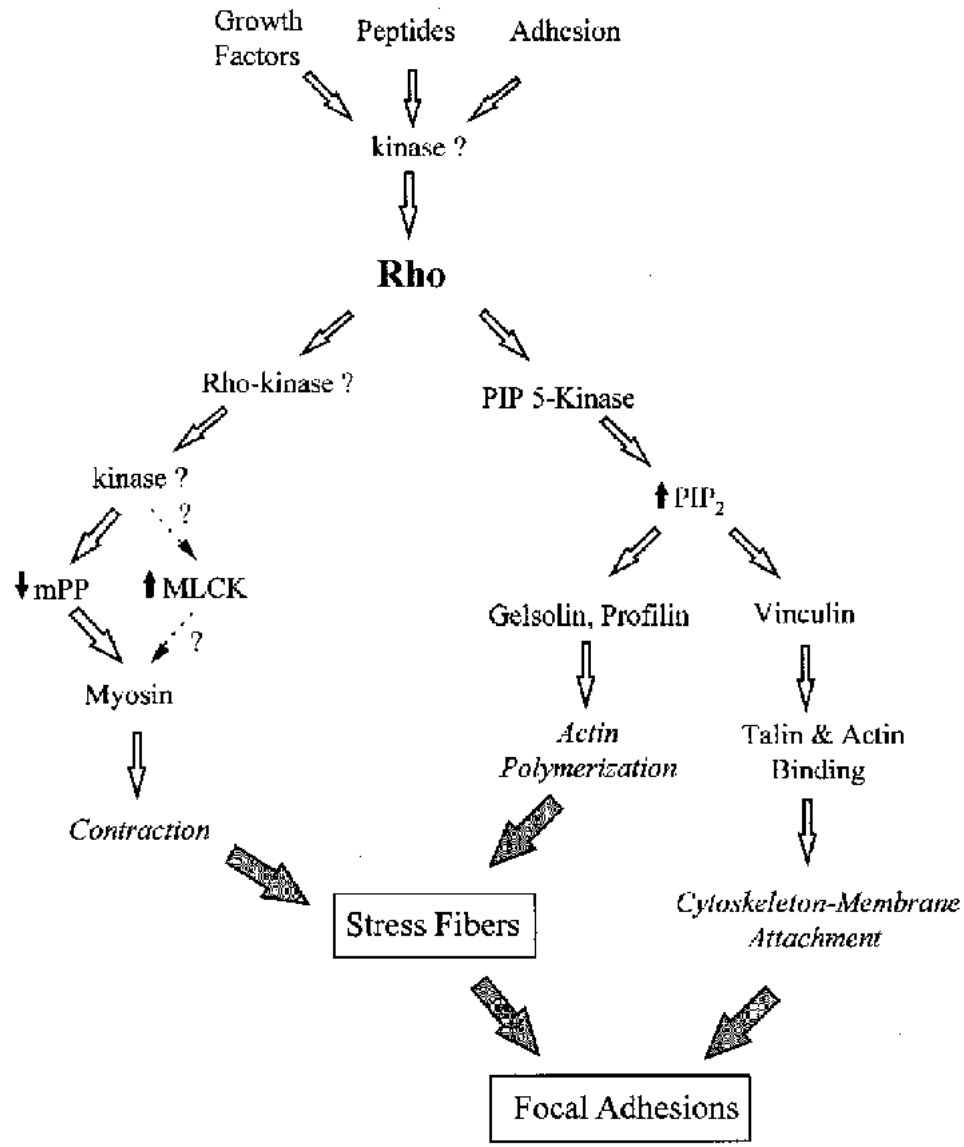

Figure 3 Pathways by which Rho regulates the actin cytoskeleton. Activation of Rho by growth factors, peptides, or adhesion is proposed to regulate the organization of the actin cytoskeleton via two synergistic pathways. In one, MLC phosphorylation is elevated via a kinase cascade that inhibits the myosin phosphatase (mPP). Stimulation of the MLCK (dotted line) may also occur, but there is no evidence for this. Light chain phosphorylation stimulates contractility. In turn, this leads to the bundling of actin filaments into stress fibers and clustering of integrins into focal adhesions. In the second, complementary pathway, Rho stimulates PIP 5-kinase, elevating PIP 2 levels. $\mathrm{PIP}_{2}$ dissociates gelsolin and profilin from actin, promoting actin polymerization. $\mathrm{PIP}_{2}$ also binds to vinculin, causing a conformational change that exposes binding sites for talin and actin, enhancing focal adhesion assembly. 


\section{Suspended cells}

A.

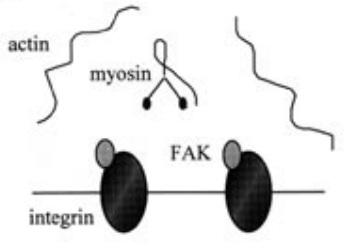

ligand
binding

\section{Adherent cells}

C.

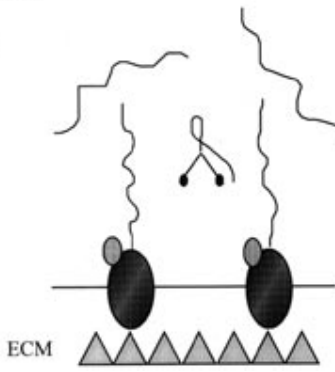

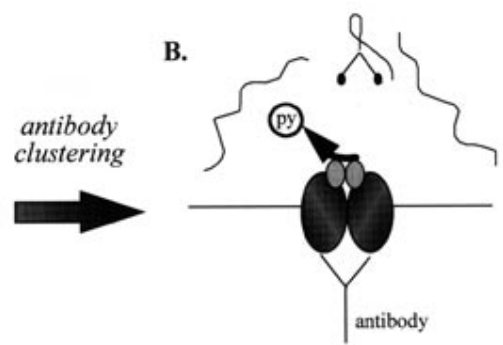

D.

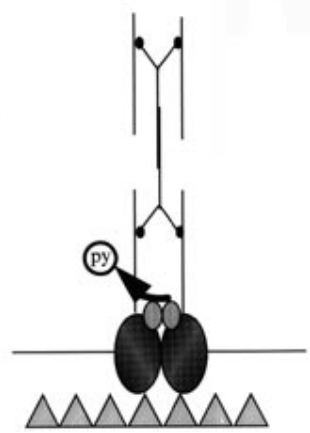

Figure 4 Model for contraction-induced formation of focal adhesions and stress fibers. In suspended cells $(A)$, integrins are dispersed over the cell surface and not attached to actin filaments. Integrins can be clustered from the outside with antibodies $(B)$, inducing FAK phosphorylation, but not attachment to actin, without ligand binding to the integrins. Adherent cells are shown in $(C)$ and $(D)$. Their integrins are bound to ECM ligands and because of this ligand occupancy become attached to actin filaments. However, in $(C)$ the cells are quiescent, Rho is inactive, and the myosin is in the nonfunctional conformation. In $(D)$ Rho activation stimulates contractility by elevating MLC phosphorylation. This leads to myosin filament formation and a force-generating interaction with actin. The tension exerted on the actin filaments bundles them into stress fibers and clusters the integrins to which they are attached. In turn, the integrin clustering stimulates FAK activity, triggering the signaling events associated with tyrosine phosphorylation in FAs. 
et al 1994) and elevated PIP $_{2}$ stimulates dissociation of both profilin and gelsolin from actin, thereby promoting actin polymerization (Lassing \& Lindberg 1985, Janmey \& Stossel 1987). In addition, PIP $_{2}$ affects the conformation of vinculin, dissociating the intramolecular head/tail interaction, thereby exposing the talin- and actin-binding sites (Gilmore \& Burridge 1996). $\mathrm{PIP}_{2}$ has also been reported to enhance the binding of $\alpha$-actinin to actin (Fukami et al 1992). Together these actions enhance stress fiber and FA formation. Inhibiting either side of the pathway illustrated in Figure 3 prevents assembly of FAs. Sequestering $\mathrm{PIP}_{2}$ by microinjection of antibodies against $\mathrm{PIP}_{2}$ into quiescent cells blocks the formation of FAs and stress fibers induced by Rho (Gilmore $\&$ Burridge 1996). Similarly, blocking contractility by a variety of agents with different modes of action inhibits the Rho-mediated assembly of stress fibers and FAs (Chrzanowska-Wodnicka \& Burridge 1996).

FA assembly is accompanied by recruitment of signaling components. Evidence has been presented that this recruitment depends on tyrosine phosphorylation (Miyamoto et al 1995b). Signaling in FAs is further discussed below, but some points are relevant here in the context of assembly. One of the most prominent signaling events within FAs is the tyrosine phosphorylation that involves FAK. FAK may associate directly or indirectly with integrins and becomes activated as a result of integrin aggregation (Kornberg et al 1991, Miyamoto et al 1995a). The model predicts that anything promoting contractility and the consequent aggregation of integrins will stimulate FAK activation (if FAK is associated with the clustered integrins), which provides an explanation for the stimulation of FAK by the diverse group of agents that act via Rho. It is generally envisaged that autophosphorylation of FAK recruits src family kinases that, in turn, phosphorylate other components, generating binding sites for signaling proteins with $\mathrm{SH} 2$ domains. A multicomponent signaling complex is assembled that depends on the initial activation of FAK (Schaller \& Parsons 1994, 1995, Miyamoto et al 1995b, Yamada \& Miyamoto 1995, Richardson \& Parsons 1995, Schwartz et al 1995). A surprising but consistent observation has been that disruption of the actin cytoskeleton, for example by treatment with cytochalasin D, inhibits the phosphorylation of FAK (Pelletier et al 1992, Haimovich et al 1993, Bockholt \& Burridge 1993, Sinnett-Smith et al 1993, Seufferlein \& Rozengurt 1994, Shattil et al 1994) as well as various downstream signaling events (Chen et al 1994). In the proposed model, FAK activation depends on the clustering of integrins from the inside by contractility. Disruption of the actin cytoskeleton would consequently block integrin aggregation driven by contractility and would account for the inhibition of FAK activity. Similarly, the model offers a potential explanation for the biphasic effects of PDGF on FAK phosphorylation. At low concentrations, PDGF stimulates FAK 
phosphorylation, but at higher concentrations it disrupts stress fibers and FAK phosphorylation is inhibited (Rankin \& Rozengurt 1994).

This model also offers an explanation for the observation that cells could spread on a low density of integrin ligand but required higher densities in order to form FAs (Massia \& Hubbell 1991). At low-ligand density, clustering the integrins would result in their dissociation from ligand. In the absence of bound extracellular ligands, the integrins would likely detach from the cytoskeleton. Therefore, a sufficiently high density of ligand on the substrate would be needed for the aggregated integrins to remain bound.

Does this model for FA formation also account for their assembly as suspended cells are plated on an ECM or during cell migration? We suspect that many aspects of the model are still relevant. Evidence shows that active Rho is required for the formation of FAs when cells are plated on ECM substrates (Hotchin \& Hall 1995). FAs appear to form spontaneously when many cells are plated on ECM, but for most cells, Rho remains in an active state for several hours even in the absence of serum. When cells are plated on ECM substrates, inhibitors of contractility block the formation of FAs or result in very small FAs that appear not to have matured into their normal organizational state (M Chrzanowska-Wodnicka \& K Burridge, unpublished observations). These results are consistent with a Rho-mediated contractile event contributing to the formation of FAs in cells spreading on ECM proteins.

\section{Tyrosine Phosphorylation and Focal Adhesion Assembly}

Several studies have shown that PTK inhibitors block the formation of FAs and stress fibers induced either by adhesion to an ECM-coated surface (Burridge et al 1992, Romer et al 1992, 1994) or by Rho activation (Seckl \& Rozengurt 1993, Chrzanowska-Wodnicka \& Burridge 1994, Ridley \& Hall 1994). Because the major sites of tyrosine phosphorylation in cultured fibroblasts are FAs and because these inhibitors decrease the tyrosine phosphorylation of FA proteins such as FAK and paxillin, the interpretation of these data was that tyrosine phosphorylation of FA components contributes to the assembly of these structures (Burridge et al 1992, Romer et al 1994). However, several lines of evidence indicate that neither the kinase inhibited in these studies nor its substrates reside in FAs. Wilson and coworkers provided evidence that FAK is not required for the formation of FAs in vascular smooth muscle cells (Wilson et al 1995). Similarly, when transformation by temperature-sensitive mutants of vsrc was shut off, FAs reassembled in the absence of tyrosine-phosphorylated FAK or paxillin (Fincham et al 1995). Cells from $\mathrm{FAK}^{-}$mice reveal prominent FAs that contain phosphotyrosine (Ilic et al 1995). Because FAK appears to be the major PTK in FAs in normal cells, this result is unexpected. In the absence of FAK, possibly other kinases are recruited to these structures, or the level or 
activity of src family kinases in FAs may increase. Alternatively, a homologue of FAK, such as CAK $\beta /$ PYK2/RAFTK (Avraham et al 1995, Lev et al 1995, Sasaki et al 1995) may be expressed in these cells, partially compensating for the lack of FAK. If there is compensation by another kinase, it is incomplete because $\mathrm{FAK}^{-}$mice die as embryos (Ilic et al 1995). The prominent phosphotyrosine in the FAs of the $\mathrm{FAK}^{-}$cells differs from results obtained using microinjection of a C-terminal FAK construct that contains the FAT sequence but lacks the kinase domain (Gilmore \& Romer 1996). This FAK construct displaces endogenous FAK from FAs and abolishes detectable phosphotyrosine at these sites. Significantly, FAs can still be assembled in these cells, but they lack detectable FAK and phosphotyrosine. These experiments suggest that FAK is not required for FA assembly or maintenance, although it appears to be important for other signaling pathways (Gilmore \& Romer 1996).

Inhibition of FAK tyrosine phosphorylation has also been observed in cells overexpressing pp41/43 ${ }^{\mathrm{FRNK}}$ (FRNK), the naturally expressed C-terminal domain of FAK, which lacks the kinase domain (Richardson \& Parsons 1996). Overexpression of FRNK also diminished the tyrosine phosphorylation of paxillin and tensin. These cells could still form focal adhesions but at a slower rate. Cell spreading on a fibronectin substrate was significantly retarded (Richardson \& Parsons 1996).

These lines of evidence indicate that although tyrosine phosphorylation and FAK activity recruit signaling components to FAs, FAK does not have a role in the assembly of the structural components. If this is the case, where do the PTK inhibitors act to block the formation of FAs and stress fibers? Evidence indicates that they act both upstream and downstream of Rho activation (Ridley \& Hall 1994, Chrzanowska-Wodnicka \& Burridge 1994, Nobes et al 1995). In the model proposed for FA assembly (Figure 3), Rho initiates a kinase cascade that results in MLC phosphorylation, thereby stimulating contractility. We suspect that one of the kinases regulating contractility may be blocked by PTK inhibitors. Alternatively, a tyrosine kinase may be involved in Rho-stimulated $\mathrm{PIP}_{2}$ synthesis.

\section{SIGNALING IN FOCAL ADHESIONS}

Integrin-mediated cell adhesion triggers tyrosine phosphorylation, ion fluxes, and lipid metabolism (Clark \& Brugge 1995, Schwartz et al 1995). Together or individually, these affect many downstream pathways, influencing events such as gene expression, progression through the cell cycle, and apoptosis. Some of the integrin-mediated signal transduction pathways, such as tyrosine phosphorylation, have been shown to be initiated from FAs, whereas others may precede FA formation and be early responses to integrin occupancy or clustering. The 
Table 4 Signaling proteins at the cytoplasmic face of focal adhesions

\begin{tabular}{lcc}
\hline \hline Tyrosine kinases & Heterotrimeric G proteins & Proteases \\
1. FAK & 6. $\gamma 5$ & 10. calpain II \\
2. src & & \\
3. csk & Adapters & Others \\
4. fyn & 7. paxillin & 11. PI3K \\
& 8. p130 $130^{\text {cas }}$ & $12 . \mathrm{LIP} 1$ \\
& 9. Grb2 &
\end{tabular}

Serine kinases

5. $\mathrm{PKC} \alpha, \delta$

1. Schaller et al 1992; 2. Kaplan et al 1994; 3. Bergman et al 1995; 4. included because of its interaction with FAK; Cobb et al 1994; 5. Jaken et al 1989, Barry \& Critchley 1994; 6. Hansen et al 1994; 7. Turner et al 1990; 8. Petch et al 1995; 9. M Kinch, unpublished observation; 10. Beckerle et al 1987; 11. Geiger et al 1992a; 12. Serra-Pages et al 1995.

idea that FAs are major sites of signal transduction is supported by the identification of multiple signaling proteins in FAs (Table 4). Numerous interactions occur between these and other signaling components involved in receptor PTK signaling pathways (Table 5). Using beads coated with antibodies or integrin ligands, Miyamoto and colleagues have identified a striking list of signaling proteins that associate with clustered integrins in a tyrosine phosphorylationdependent manner (Miyamoto et al 1995b). Many have not been seen in FAs, but the bead technique may allow easier visualization of components that associate transiently with integrins. Alternatively, some of these components may be involved with endocytosis, a process also dependent on tyrosine phosphorylation (Shimo et al 1993, Salamero et al 1995). In the following discussion, we concentrate on signaling involving tyrosine phosphorylation.

\section{Tyrosine Phosphorylation}

Early work on tyrosine phosphorylation in FAs has been reviewed (Burridge et al 1988). A link between integrins and tyrosine phosphorylation was first demonstrated in platelets, where thrombin was shown to trigger tyrosine phosphorylation in an integrin-dependent fashion (Ferrell \& Martin 1989, Golden \& Brugge 1989). These observations were followed by studies with cells in culture, where it was also shown that integrin clustering or integrin-mediated adhesion stimulate tyrosine phosphorylation of a small set of proteins (Guan et al 1991, Kornberg et al 1991, Burridge et al 1992). Coincident with these studies was the discovery of a cytoplasmic PTK that localizes to FAs, the FA kinase (pp125 $5^{\text {FAK }}$ or FAK) (Schaller et al 1992, Hanks et al 1992). The discovery of FAK galvanized the field, and FAK was shown to be the most prominent of the tyrosine-phosphorylated proteins in cells responding to integrin clustering 


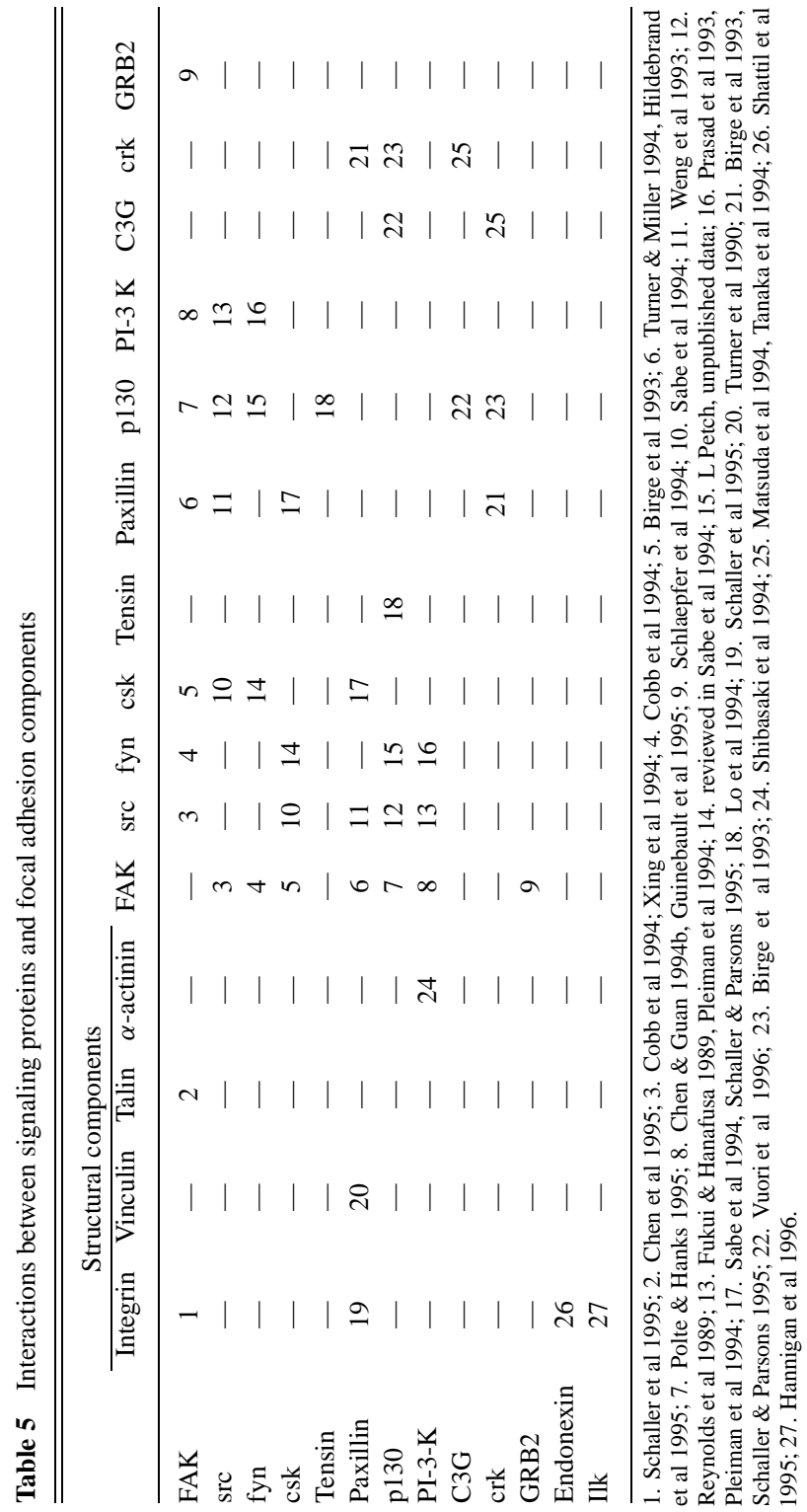


or integrin-mediated adhesion (Burridge et al 1992, Hanks et al 1992, Guan \& Shalloway 1992, Kornberg et al 1992, Lipfert et al 1992). Several other FA proteins were identified as also becoming tyrosine-phosphorylated in response to integrin-mediated adhesion. These included paxillin (Burridge et al 1992), tensin (Bockholt \& Burridge 1993), PI 3-kinase (Chen \& Guan 1994a), and p130 cas (Petch et al 1995, Vuori \& Ruoslahti 1995, Nojima et al 1995). Notably, the more major proteins in FAs - talin, vinculin, integrins - contain little or no phosphotyrosine. This contrasts with the situation in src-transformed cells in which low levels of phosphotyrosine are detected in these proteins.

FAK is a cytoplasmic PTK with three domains. The central catalytic domain separates an $\mathrm{N}$-terminal domain, shown to bind to $\beta 1$ integrin cytoplasmic domain peptides (Schaller et al 1995), and a C-terminal domain, which contains a FA-targeting (FAT) sequence (Hildebrand et al 1993). This latter domain contains binding sites for at least two FA proteins, paxillin and talin (Turner \& Miller 1994, Chen et al 1995, Hildebrand et al 1995, Tachibana et al 1995). Lewis \& Schwartz (1995) found that association of FAK with clustered integrins in vivo depended on the most C-terminal 13 residues of the $\beta_{1}$ cytoplasmic domain. This was also the sequence required for co-clustering talin and paxillin with integrins, possibly indicating that one or other might contribute to FA targeting. In addition, FAK constructs containing the paxillin-binding sequence target to FAs, but fail to do so if this binding sequence is disrupted (Tachibana et al 1995). In these experiments, the interaction with talin was not examined, but it might also contribute to targeting FAK to FAs. These results support the idea that the interaction of FAK with paxillin or talin targets it to FAs. However, Miyamoto and colleagues found that simple aggregation of integrins was sufficient to co-cluster FAK but not talin or paxillin (Miyamoto et al 1995a). Co-clustering of talin required both aggregation and ligand occupancy, whereas co-clustering of paxillin required tyrosine phosphorylation as well.

The significance of the interaction of the $\mathrm{N}$-terminal domain with integrin peptides is not obvious because this region does not appear to be involved in targeting FAK to FAs. Possibly this interaction functions in the activation of FAK, but most of the evidence indicates that clustering of integrins triggers FAK activation (Kornberg et al 1991, Defilippi et al 1994) and that ligand occupancy is not involved (Miyamoto et al 1995a). However, clustering of one integrin with an activating antibody failed to induce tyrosine phosphorylation (Pelletier et al 1995). Integrin aggregation may dimerize FAK, and thereby stimulate transphosphorylation and activation. This would be consistent with the model for activation of receptor PTKs (Ullrich \& Schlessinger 1990).

For many receptor PTKs, ligand binding triggers autophosphorylation. The resulting phosphotyrosines in the receptor cytoplasmic domain bind $\mathrm{SH} 2$ 
domain-containing proteins. A similar situation is found for FAK. Several sites of tyrosine phosphorylation have been identified that recruit specific proteins via their SH2 domains (Schaller et al 1994, Schlaepfer et al 1994). The major site of tyrosine phosphorylation in FAK is Tyr-397, which arises through autophosphorylation (Schaller et al 1994). This generates a binding site for the SH2 domains of $\mathrm{pp} 60^{\mathrm{src}}$ and $\mathrm{pp} 59^{\text {fyn }}$, both of which have been shown to complex with FAK in cells (Cobb et al 1994, Schlaepfer et al 1994, Xing et al 1994). These kinases phosphorylate additional sites in FAK and may stimulate FAK activity (Schlaepfer et al 1994, Calalb et al 1995). One of these sites, Tyr-925, complexes with the adapter protein Grb2 (Schlaepfer et al 1994). In normal cells, the association of Grb2 with FAK is dependent on integrin-mediated adhesion, but in v-src-transformed cells, FAK is constitutively tyrosine-phosphorylated and bound to Grb2. In these src-transformed cells, Grb2 is further associated with Sos, a Ras GTP/GDP exchange factor that activates the MAP kinase pathway (Schlaepfer et al 1994). This pathway may also operate in normal cells because MAP kinase activation has been observed in cells plated onto fibronectin in the absence of growth factors (Chen et al 1994, Schlaepfer et al 1994, Morino et al 1995, Zhu \& Assoian 1995), and antibody-clustering of $\alpha_{2} \beta_{1}$ integrins in lymphocytes elevates the level of Ras-GTP (Kapron-Bras et al 1993). However, MAP kinase activation may be triggered by other signaling cascades initiated by integrin-mediated adhesion.

The association of $\mathrm{pp} 60^{\mathrm{src}}$ and $\mathrm{pp} 59^{\mathrm{fyn}}$ with FAK raises the question of which PTK is responsible for the tyrosine phosphorylation of specific FA proteins. Examining cells from transgenic mice that had had their src, fyn, or yes genes individually knocked out revealed that the patterns of tyrosine phosphorylation upon adhesion to fibronectin resembled that in control cells, with the exception of p130 cas (Bockholt \& Burridge 1995). The tyrosine phosphorylation level of p130 cas was reduced in the $f^{-} n^{-}$and $y e s^{-}$cells, and to a particularly low level in the $s r c^{-}$cells, suggesting that its phosphorylation is dependent on src and to a lesser extent on the other src family kinases. Although many of their characteristics resemble normal cells, the $\mathrm{src}^{-}$cells spread more slowly on fibronectin (Kaplan et al 1995). Besides FAK, one of the major tyrosine-phosphorylated proteins in FAs is paxillin (Turner 1994). Paxillin binds FAK and is a substrate for FAK in vitro and in vivo (Bellis et al 1995, Hildebrand et al 1995, Schaller $\&$ Parsons 1995). Autophosphorylation of FAK on Tyr-397 is required for paxillin phosphorylation (Schaller \& Parsons 1995), which suggests that src or fyn may be involved, given that these two kinases bind to this site. Paxillin is a substrate in vitro not only for FAK, but also for src and csk (the kinase that regulates src activity by phosphorylation of its C-terminal tyrosine) (Schaller $\&$ Parsons 1995). All three kinases phosphorylate sites in vitro that are also 
phosphorylated in vivo (Schaller \& Parsons 1995). These authors suggest a model whereby cell adhesion results in FAK autophosphorylation. This phosphorylation recruits src/fyn or csk by binding to the $\mathrm{SH} 2$ domains of these kinases. In turn, these phosphorylate paxillin on multiple sites. The absence of an obvious decrease in paxillin tyrosine phosphorylation in the $\mathrm{src}^{-}$cells may reflect redundancy in the system with fyn or csk replacing src (Bockholt \& Burridge 1995).

Csk is an important regulator of the src family kinases. It inhibits their activity by phosphorylating the $\mathrm{C}$-terminal tyrosine residue. This $\mathrm{C}$-terminal phosphotyrosine then participates in an intramolecular association with its own $\mathrm{SH} 2$ domain, leading to a steric inhibition of the kinase domain (Cooper \& Howell 1993). Overexpression of csk leads to its detection within FAs (Bergman et al 1995), suggesting that it is normally present but below the level of detection. Deletion of Csk results in src that is not phosphorylated on its C-terminal tyrosine (Tyr-527), and src now becomes detected in focal adhesions (Kaplan et al 1994). Similarly, mutating tyr-527 to phenylalanine, which prevents phosphorylation, results in src becoming prominently associated with FAs. Interestingly, the targeting of src to FAs occurs in the absence of the kinase domain and requires an intact SH3 domain (Kaplan et al 1994). The SH3 domain has been shown previously to bind to paxillin (Weng et al 1993). This may be the interaction that targets src to FAs, whereas the src SH2 interaction with FAK may activate src by displacing the intramolecular association between the $\mathrm{SH} 2$ domain and Tyr-527. A src construct lacking the kinase domain, but with intact SH2 and SH3 domains, elevates phosphotyrosine in FAs, particularly in FAK (Kaplan et al 1994). The mechanism for this is uncertain, but it may reflect the src SH2 domain protecting tyrosine-phosphorylated residues from tyrosine phosphatases. In csk $^{-}$cells the level of phosphotyrosine in paxillin is increased, consistent with src family kinases being responsible (Nada et al 1994, Thomas et al 1995). The relationship of src and fyn has been investigated in the csk background using double knockouts (Thomas et al 1995). These authors observed a decrease in the total level of phosphotyrosine in the $\mathrm{src}^{-} \mathrm{csk}^{-}$cells but not the fyn ${ }^{-} \mathrm{csk}^{-}$cells, suggesting that src is more critical than fyn to the elevation of phosphotyrosine in the $\mathrm{csk}^{-}$cells. However, the elevated phosphotyrosine in paxillin was partially decreased by the introduction of either the $s \mathrm{rc}^{-}$or $f \mathrm{yn}^{-}$mutation, consistent with both these kinases having a role in phosphorylating paxillin.

Another major tyrosine-phosphorylated protein in FAs is p130 $0^{\text {cas }}$ (Petch et al 1995). The data from the $\mathrm{src}^{-}$cells suggest that much of the tyrosine phosphorylation of this protein is also from the activity of src (Bockholt \& Burridge 1995). Like paxillin, this is a protein that interacts with other signaling proteins 
(Table 5). The sequence of $130^{\text {cas }}$ reveals that it contains one $\mathrm{SH} 3$ domain and numerous tyrosines within the consensus-binding sites for the $\mathrm{SH} 2$ domains of src and crk (Sakai et al 1994). Both paxillin and p130 cas bind the adapter protein crk, which consists of SH2 and SH3 domains (Birge et al 1992, 1993, Schaller \& Parsons 1995). The latter mediates interaction with two guanine nucleotide exchange factors for ras, Sos and C3G (Matsuda et al 1994, Tanaka et al 1994). The multiple interactions of paxillin and $\mathrm{p} 130^{\mathrm{cas}}$ with other signaling proteins has led to the general view that these proteins may be equivalent to the IRS-1 protein in insulin-signaling pathways. IRS-1 becomes tyrosinephosphorylated on multiple sites in response to insulin binding to the insulin receptor. This provides a scaffold for downstream signaling components to bind via their SH2 domains. Similarly, following their tyrosine phosphorylation, paxillin and p130 cas may also act as scaffolds, recruiting other signaling proteins into a complex that activates separate or overlapping signaling pathways.

Very little is known about tyrosine phosphatases (PTPs) in FAs. The transmembrane PTP, LAR has been detected in the FAs of some cells, together with an interacting cytoplasmic protein, LIP (Serra-Pages et al 1995). However, in several cell types LAR has not been detectable in FAs, indicating that other PTPs may be present (G Schneider \& K Burridge, unpublished observations).

\section{Does Integrin-Mediated Adhesion Activate Rho?}

The formation of stress fibers and FAs requires activated Rho (Ridley \& Hall 1992). Cells plated on an ECM in the absence of growth factors also develop FAs, raising the possibility that integrin-mediated adhesion activates Rho, thus providing the stimulus for FA formation. Supporting this idea was the demonstration that $\mathrm{PIP}_{2}$ levels increase when cells adhere to ECM McNamee et al 1993) and that this depended on Rho (Chong et al 1994). These results indicate that integrin engagement activates Rho. However, this has been challenged by the experiments of Hotchin \& Hall (1995), who found that quiescent cells, with low levels of active Rho failed to form FAs or stress fibers when plated on fibronectin substrates for 30-45 min. Under these conditions, FAs formed rapidly upon Rho activation. Similar experiments were performed by Barry and coworkers who also observed a failure to form FAs and stress fibers 30 min after plating quiescent cells on fibronectin (Barry et al 1996). However, in this study FAs and stress fibers were seen $3 \mathrm{~h}$ after adhesion to fibronectin, indicating that this interaction does activate Rho, albeit inefficiently or with a delayed time course.

The activation of Rho in response to integrin-mediated adhesion may involve an arachidonic acid/leukotriene pathway. The spreading of cells on ECM substrates stimulates and requires activation of PKC (Chun \& Jacobson 1992, 1993, 
Vuori \& Ruoslahti 1993) and release of arachidonic acid (Chun \& Jacobson 1992). Blocking the metabolism of arachidonic acid to leukotrienes prevents HeLa cells spreading on a collagen matrix, and this block can be partially overcome by added leukotrienes (Chun \& Jacobson 1992). Notably, leukotrienes have been reported to stimulate Rho (Peppelenbosch et al 1995). Together these results suggest a pathway in which leukotrienes may link integrin-mediated adhesion to Rho activation. Leukotriene synthesis and stimulation of Rho also provide a connection between Rac and Rho in cells responding to EGF (Peppelenbosch et al 1995). The activation of Rac is associated with extensive membrane ruffling (Ridley et al 1992), and this phenotype resembles the behavior of cells freshly plated on ECM. Indeed, the behavior of cells spreading on ECM resembles cells responding sequentially to cdc42, Rac, and finally Rho. Initial adhesion is associated with production of filopodia (the cdc42 phenotype) (Albrecht-Buehler 1976), followed by lamellipodia (the Rac phenotype) and, finally, when cells have become well spread, the development of stress fibers and FAs (the Rho phenotype). A hierarchy has been demonstrated previously, with cdc42 upstream of rac, which is upstream of Rho (Nobes \& Hall 1995). It is conceivable, therefore, that this is also the pathway from integrin-mediated adhesion to activation of Rho, going via cdc42, Rac, and the synthesis of leukotrienes.

An alternative pathway by which Rho may become activated during adhesion involves Vav, a possible Rho GEF. In platelets, Vav becomes tyrosinephosphorylated upon platelet activation by thrombin or collagen (Cichowski et al 1996). The stimulation by collagen occurs via the integrin $\alpha_{2} \beta_{1}$, indicating that in some circumstances Vav regulation is integrin-dependent. Vav binds the FA protein zyxin, contains one $\mathrm{SH} 2$ domain, two $\mathrm{SH} 3$ domains, a pleckstrin homology domain, and a dbl homology domain. The latter is associated with guanine nucleotide exchange. Whether Vav acts on Rho or another ras-related protein is controversial, but the phenotype of cells transformed by Vav suggests that it acts directly or indirectly on Rho (Khosravi-Far et al 1994). Vav is normally confined to hematopoietic cells, but a widely distributed isoform, Vav2, has been identified (Henske et al 1995). Vav itself becomes phosphorylated on serine and tyrosine residues and is probably involved in several signaling cascades (Gulbins et al 1993, Uddin et al 1995, Matsuguchi et al 1995). If Vav2 becomes phosphorylated by integrin engagement, this would suggest one way by which adhesion might activate Rho. Because Rho enhances adhesion and spreading, the activation of Rho by adhesion suggests a positive feedback loop. Positive feedback loops have previously been suggested to occur during adhesion and spreading in the context of PKC activation (Chun \& Jacobson 1993). 


\section{Focal Adhesions and Growth Control}

It has been long known that most normal cells in culture are anchorage dependent, i.e. they require attachment to a substrate in order to go through the cell cycle (Stoker et al 1968). The requirement for anchorage is abolished by many different oncogenes. Suspension of normal cells arrests not only DNA synthesis, but also inhibits RNA and protein synthesis (Otsuka \& Moskowitz 1975, Benecke et al 1978, 1980, Farmer et al 1978, Ben-Ze'ev et al 1980). Cell cycle progression is blocked in $\mathrm{G}_{1}$ by suspension (Otsuka \& Moskowitz 1975). Clearly with normal cells, adhesion-dependent signals regulate many activities and permit cells to respond to growth factors. Several integrin-mediated signaling pathways have been implicated. Elevated intracellular $\mathrm{pH}$ has been associated with growth of normal cells, and this is regulated by integrins via the $\mathrm{Na}^{+} / \mathrm{H}^{+}$antiporter (Schwartz et al 1989, 1990, 1991a,b, Ingber et al 1990). Integrins have also been linked to elevated intracellular $\mathrm{Ca}^{2+}$ (Pelletier et al 1992, Leavesley et al 1993, Schwartz et al 1993, Schwartz 1993, Schwartz \& Denninghoff 1994). In endothelial cells, the integrin-dependent elevation in intracellular $\mathrm{Ca}^{2+}$ involves an integrin-associated protein (IAP) (Schwartz et al 1993). The mechanism by which integrins elevate intracellular $\mathrm{Ca}^{2+}$ has not been resolved, but intracellular $\mathrm{Ca}^{2+}$ has been associated with many mitogenic signals and pathways. Intracellular $\mathrm{Ca}^{2+}$ levels are frequently elevated by release from intracellular stores via a pathway that involves $\mathrm{PIP}_{2}$ hydrolysis and the generation of inositol trisphosphate $\left(\mathrm{IP}_{3}\right)$ (Berridge 1993). As discussed above, $\mathrm{PIP}_{2}$ levels are elevated by adhesion in a Rho-dependent manner (McNamee et al 1993, Chong et al 1994). One pathway from growth factor receptors involves activation of phospholipase $\mathrm{C}$, which hydrolyzes $\mathrm{PIP}_{2}$ to generate $\mathrm{IP}_{3}$ and diacyl glycerol. These act as second messengers elevating intracellular $\mathrm{Ca}^{2+}$ and activating PKC. The decrease in $\mathrm{PIP}_{2}$ that occurs with suspension of cells deprives PLC of its substrate and has been correlated with the inability of cells in suspension to respond to growth factors, even though the growth factors bind to their receptor PTKs (McNamee et al 1993).

Many lines of evidence point to a collaboration between the signals emanating from FAs and growth control. For example, in collagen gels, cells show high proliferation rates if the gel is anchored so that the cells generate isometric tension and develop stress fibers. In contrast, cells in free-floating gels do not develop isometric tension or stress fibers, and the cells become arrested for DNA synthesis and proliferation (Lin \& Grinnell 1993, Grinnell 1994). With adherent cells in culture, several mitogens stimulate tyrosine phosphorylation of the same repertoire of FA proteins (FAK, paxillin, p130 ${ }^{\text {cas }}$, tensin) (Zachary et al 1992, 1993, Kumagai et al 1993, Sinnett-Smith et al 1993, Hordijk et al 1994, Seufferlein \& Rozengurt 1994). Most, if not all, of these mitogens stimulate 
Rho, contractility, and the formation of FAs in quiescent cells. Introduction of activated Rho into quiescent cells is itself sufficient to stimulate progression through the cell cycle and DNA synthesis (Olson et al 1995).

Adhesion to ECM activates the MAP kinase pathway, which is also triggered by many growth factors. MAP kinase activation may be via Grb2 binding to phosphorylated Tyr-925 in FAK (Schlaepfer et al 1994), but other adapter proteins interact with FA proteins, such as paxillin and p130 cas (Table 5) and may provide parallel routes to MAP kinase activation. Adhesion alone is an insufficient stimulus to activate the MAP kinase pathway if Rho is not active (Hotchin \& Hall 1995). It is not clear why growth factors and adhesion to ECM should both stimulate MAP kinase activation. The experimental paradigm of plating suspended cells on ECM substrates such as fibronectin is clearly artificial. One can imagine, however, that an equivalent situation is encountered normally when circulating cells adhere to a damaged blood vessel wall or when cells respread after mitosis. Similarly, during migration, the formation of new adhesions may trigger localized activation of MAP kinase pathways.

Is FAK involved in the synergy between integrin and growth factor signaling? Analysis of the role of FAK in growth control has not been possible with the $\mathrm{FAK}^{-}$cells because they were transfected with activated $\mathrm{p} 53$ to promote growth (Ilic et al 1995). However, in an experimental model discussed above, FAK function was analyzed using microinjection of a $\mathrm{C}$-terminal construct to displace endogenous FAK from FAs (Gilmore \& Romer 1996). Displacement of FAK from FAs significantly decreased the number of cells entering DNA synthesis in response to stimulation with serum. This finding supports the idea that signaling from FAK contributes to and may be necessary for normal cells to respond to growth factors and to display anchorage-dependent growth. A similar conclusion was reached in experiments where epithelial cells were transfected with constitutively active FAK. This rendered the epithelial cells anchorage independent and even made them tumorigenic (Frisch et al 1996). In the model for FA formation discussed above, FAK activation results from integrin clustering induced by contractility within the microfilament system. This model predicts that disruption of the cytoskeleton should prevent FAK activation, which would resemble loss of adhesion in terms of growth control. This indeed is the case. Disruption of the cytoskeleton with cytochalasin mimics the effect of cell suspension, blocking cells that are anchorage dependent in $\mathrm{G}_{1}$ (Bohmer et al 1996).

Direct interactions between integrins and growth factor-signaling components have been identified. In response to insulin stimulation, IRS- 1 associates with the vitronectin receptor, $\alpha_{\mathrm{v}} \beta_{3}$. Insulin stimulates growth of cells adhering to vitronectin more effectively than it stimulates cells adhering to other ECM proteins (Vuori \& Ruoslahti 1994). The FGF receptor $f l g$ has been identified 
in FA complexes isolated on fibronectin-coated beads (Plopper et al 1995). In addition, numerous signaling components associated with receptor PTKs also associate with clustered integrins (Miyamoto et al 1995b).

The interplay between integrins and growth factors is illustrated by the growth and differentiation of myoblasts. Sastry and colleagues have found that ectopic expression of the $\alpha_{5}$ integrin subunit inhibits differentiation, promoting proliferation. In contrast, ectopic expression of $\alpha_{6}$ promotes differentiation and inhibits proliferation in this system (Sastry et al 1996). Chimeric constructs, in which the cytoplasmic domains were truncated or swapped, demonstrated that these effects depended on the $\alpha$ subunit cytoplasmic domains. The ectopic expression of $\alpha_{5}$ changed the response of myoblasts to specific growth factors. For example, normally both TGF $\beta$ and bFGF inhibit proliferation and stimulate differentiation, but following transfection with the $\alpha_{5}$ subunit, these growth factors inhibited differentiation. However, only bFGF stimulated proliferation, whereas TGF $\beta$ now induced apoptosis (Sastry et al 1996). Ectopic expression of $\alpha_{5}$ in other situations also affects growth characteristics. For example, expression of $\alpha_{5}$ in tumor cells deficient in this integrin subunit has been correlated with restoration of a normal phenotype and anchorage-dependent growth (Giancotti \& Ruoslahti 1990). These effects of $\alpha_{5}$ expression on tumor cell growth are complex. Ectopic expression of $\alpha_{5}$ inhibits anchorage-independent growth, but it promotes growth on an appropriate ECM substrate (Varner et al 1995). These findings imply that a negative growth signal is transmitted by the unengaged $\alpha_{5} \beta_{1}$ integrin, but a positive proliferation signal is triggered upon ligand binding to this integrin. Clearly, different $\alpha$ subunits generate distinct signals, although very little is known about their nature. Integrin cytoplasmic domains also generate growth-related signals as evidenced by the inhibition of cell cycle progression and proliferation induced by ectopic expression of the $\beta_{1 \mathrm{C}}$ alternatively spliced cytoplasmic isoform (Meredith et al 1995, Fornaro et al 1995). $\beta_{1 \mathrm{C}}$ has been identified in platelets, megakaryocytes, and some other blood cells (Languino \& Ruoslahti 1992). It is absent from growing endothelial cells but is induced when endothelial cells are growth arrested by exposure to tumor necrosis factor $\alpha$ (Fornaro et al 1995).

The expression of $\alpha_{5}$ integrin in transformed cells restores more normal growth characteristics and the formation of FAs. As mentioned above, in normal cells the ability to form FAs correlates with anchorage-dependent growth, and disruption of FAs leads to cell cycle arrest. However, a paradoxical situation is seen in cells in which the levels of vinculin or $\alpha$-actinin are decreased, for example, by antisense cDNA constructs. Depressing the level of either protein results in decreased FAs, increased motility, and anchorage-independent growth (Rodriguez Fernandez et al 1992, 1993, Gluck et al 1993, Gluck \& Ben-Ze'ev 
1994). Cells with decreased levels of vinculin or $\alpha$-actinin form tumors when injected into nude mice. Moreover, several transformed cells or tumors show decreased expression of vinculin or $\alpha$-actinin. Elevating the levels of these proteins restores a more normal phenotype, including anchorage-dependent growth and suppression of tumorigenicity (Gluck et al 1993, Rodriguez Fernandez et al 1992). A possible explanation for these observations relates to the fact that both vinculin and $\alpha$-actinin are major $\mathrm{PIP}_{2}$-binding proteins (Fukami et al 1994). Levels of $\mathrm{PIP}_{2}$ are reduced when normal cells are suspended, and this has been correlated with growth arrest of cells in suspension (McNamee et al 1993). If vinculin and $\alpha$-actinin are major sinks for cytoplasmic $\mathrm{PIP}_{2}$, it is conceivable that reducing their levels increases PIP $_{2}$ availability to hydrolysis by PLC and thus permits suspended cells to respond to growth factor stimulation by $\mathrm{PIP}_{2}$ hydrolysis. It will be important to determine whether vinculin and $\alpha$-actinin buffer $\mathrm{PIP}_{2}$ levels. If incorporation of vinculin and $\alpha$-actinin into FAs releases their bound $\mathrm{PIP}_{2}$, this would also increase the $\mathrm{PIP}_{2}$ available for hydrolysis and provide another link between focal adhesions and mitogenic pathways.

\section{Apoptosis}

Cooperativity between integrin-mediated adhesion and growth factors is also seen in relation to apoptosis. Loss of adhesion blocks progression through the cell cycle for normal anchorage-dependent cells. But more than that, for some cells it also induces apoptosis (programmed cell death), particularly in the absence of growth factors (Meredith et al 1993, Frisch \& Francis 1994, Re et al 1994). Engagement of different integrins prevents apoptosis in different cell types. Thus the $\alpha_{5}$ integrin subunit increases survival of CHO cells adhering to fibronectin in the absence of growth factors (Zhang et al 1995). Similarly, in muscle cells expressing ectopic $\alpha_{5}$, survival is increased in the presence of bFGF, whereas untransfected cells become apoptotic (Sastry et al 1996). $\beta_{1}$ integrins prevent apoptosis in mammary epithelial cells adhering to basement membranes (Boudreau et al 1995). In contrast, disruption of $\alpha_{\mathrm{v}} \beta_{3}$ interactions promote apoptosis in colon carcinoma cells, endothelial cells, and melanoma cells (Bates et al 1994, Brooks et al 1994, Montgomery et al 1994). The term anoikis (Greek for homelessness) has been coined to describe the apoptosis that results from loss of normal adhesion to ECM (Frisch \& Francis 1994).

Is there a role for FAK in integrin-mediated survival versus apoptosis? Meredith and coworkers demonstrated that apoptosis of suspended cells could be prevented by elevating tyrosine phosphorylation, consistent with, but not proving, a role for FAK in this process (Meredith et al 1993). The involvement of FAK in apoptosis/survival has been approached recently in several ways. Reducing the level of FAK in several tumor cell lines with antisense oligonucleotides induced detachment from the substrate and a high incidence 
of apoptosis (Xu et al 1996). Interestingly, normal cells did not respond by detachment or apoptosis, which led these investigators to propose targeting FAK with antisense oligonucleotides as a potential strategy for treating tumors. However, others have found that perturbations of FAK in normal cells lead to apoptosis. Apoptosis was induced in chicken embryo fibroblasts by microinjection of either an antibody against FAK or integrin cytoplasmic domain peptides that correspond to the region shown to bind FAK in vitro (J Hungerford et al, manuscript submitted). Epithelial cell lines that go into apoptosis upon suspension were rescued by transfection with constitutively activated forms of FAK (Frisch et al 1996). Rescue from apoptosis did not occur if the cells were transfected with a kinase-dead mutant of FAK or with a mutant in which the major autophosphorylation site in FAK had been deleted. Together these results provide strong support for the idea that a major function for FAK is to signal to a cell that it is in contact with ECM. In the absence of this signal, cells will go into apoptosis. With tumor cells, growth becomes anchorage independent owing to activation of oncogenes that short circuit the FAK pathway. It is interesting that many invasive tumors display elevated expression of FAK, which may contribute to their anchorage-independent growth (Owens et al 1995).

\section{TELEOLOGY}

Why do cells in culture form FAs? The existence of FAs and stress fibers is closely correlated. They have little to do with cell migration; they are absent from many migratory cells and prominent in the least motile cells (Burridge 1981). In nonmuscle tissues, large bundles of actin filaments, which are contractile, are common in two circumstances: cytokinesis and wound contracture (Gabbiani et al 1973). We suspect that the origin of stress fibers and FAs reflects the response of cells in culture to an apparent wound environment. Many of the agents that activate Rho are released by platelets or other cells in response to wounding (e.g. LPA, thrombin, endothelin). Some of these factors are present in serum; thus cells cultured with serum respond as if in a wound. These factors stimulate Rho-mediated contraction. However, because the underlying substrate is rigid and the adhesions to it are strong, contraction generates isometric tension, leading to the development of stress fibers and FAs. For most tissues, wounding is also a potent mitogenic signal. Cells closing a wound proliferate and normally this ceases once the wound has been repaired. A parallel situation is seen experimentally with cells in collagen gels. If contraction of the gel is physically restricted, the cells develop isometric tension and prominent stress fibers (Tomasek et al 1992, Grinnell 1994). Under these conditions, the cells respond to mitogens by proliferation. Following release of tension, stress fiber disassembly occurs and is accompanied by a return to quiescence and a loss of responsiveness to growth factors (Grinnell 1994). Similarly, when 
normal cells in culture are detached from a substrate or are prevented from spreading and generating tension, they become refractory to growth factors. Not only does the formation of FAs reflect the response of cells in culture to a wound environment, but the signaling at FAs may also relate to this wound response. The clustering of integrins stimulated by contractility activates FAK and triggers signaling cascades that synergize with growth factors. Together these responses combine in tissues to close a wound both by contraction and cell proliferation. In tissue culture, they contribute to the appearance of stress fibers and FAs and to anchorage-dependent growth.

\section{PERSPECTIVES FOR THE FUTURE}

The last few years have witnessed considerable progress in the field of focal adhesion research. Particularly rapid advances have been made identifying downstream pathways from Rho. Because of this, it seems likely that the steps from the activation of Rho to the assembly of focal adhesions will be elucidated in the near future. Many of the structural interactions that occur in FAs may take longer to resolve. We anticipate that FAs will continue to serve as a useful model for studying the signaling that is initiated in response to adhesion to ECM. Many of the presumptive signaling components in FAs, such as paxillin and p130 ${ }^{\text {cas }}$, have yet to be assigned a function. Experimental strategies aimed at determining their functions are being actively pursued. Perhaps the greater challenge will be to unravel the web of signaling pathways that emerge from FAs. The interactions between integrin-mediated signals and the signals generated in response to growth factors promise to be fertile grounds, relevant to understanding not only anchorage-dependent growth, but also differentiation and apoptosis.

\section{ACKNOWLEDGMENTS}

We thank many colleagues for sending us preprints of their work. However, we apologize to the many whose work we have failed to cite because of space limitations. A search generated over 1500 papers in this area in the past five years. We are indebted to Alexey Belkin, Andrew Gilmore, Lew Romer, Patricia Saling, and Mike Schaller for their comments and suggestions on this review. The authors were supported by National Institutes of Health grants GM29860 and HL45100.

\footnotetext{
Any Annual Review chapter, as well as any article cited in an Annual Review chapter, may be purchased from the Annual Reviews Preprints and Reprints service.

1-800-347-8007; 415-259-5017; email: arpr@class.org Visit

the Annual Reviews home page at http://www.annurev.org.
} 
Adams JC, Watt FM. 1993. Regulation of development and differentiation by the extracellular matrix. Development 117:1183-98

Adelstein RS, Conti MA. 1975. Phosphorylation of platelet myosin increases actinactivated myosin ATPase activity. Nature 256:597-98

Aepfelbacher M. 1995. ADP-ribosylation of Rho enhances adhesion of U937 cells to fibronectin via the $\alpha_{5} \beta_{1}$ integrin receptor. FEBS Lett. 363:78-80

Aktories K, Hall A. 1989. Botulinum ADPribosyltransferase $\mathrm{C} 3$ : a new tool to study low molecular weight GTP-binding proteins. Trends Pharmacol. Sci. 10:415-18

Albrecht-Buehler G. 1976. Filopodia of spreading 3T3 cells: Do they have a substrateexploring function? J. Cell Biol. 69:275-86

Alessi D, MacDougall LK, Sola MM, Ikebe M, Cohen P. 1992. The control of protein phosphatase 1 by targeting subunits. The major myosin phosphatase in avian smooth muscle is a novel form of protein phosphatase 1. Eur. J. Biochem. 210:1023-35

Amano M, Mukai H, Ono Y, Chihara K, Matsui T, et al. 1996. Identification of a putative target for rho as the serine-threonine kinase protein kinase N. Science 271:648-50

Avraham S, London R, Fu Y, Ota S, Hiregowdara D, et al. 1995. Identification and characterization of a novel related adhesion focal tyrosine kinase (RAFTK) from megakaryocytes and brain. J. Biol. Chem. 270:2774251

Baciu PC, Goetinck PF. 1995. Protein kinase C regulates the recruitment of syndecan-4 into focal contacts. Mol. Biol. Cell 6:1503-13

Balzac F, Belkin AM, Koteliansky VE, Balabanov YV, Altruda F, et al. 1993. Expression and functional analysis of a cytoplasmic domain variant of the beta-1 integrin subunit. $J$. Cell Biol. 121:171-78

Balzac F, Retta SF, Albini A, Melchiorri A, Koteliansky VE, et al. 1994. Expression of beta-1B integrin isoform in $\mathrm{CHO}$ cells results in a dominant negative effect on cell adhesion and motility. J. Cell Biol. 127:557-65

Barry ST, Critchley DR. 1994. The RhoAdependent assembly of focal adhesions in Swiss 3T3 cells is associated with increased tyrosine phosphorylation and the recruitment of both pp $125^{\mathrm{FAK}}$ and protein kinase C-delta to focal adhesions. J. Cell Sci. 107:2033-45

Barry ST, Ridley AJ, Flinn HM, Humphries MJ, Critchley DR. 1996. Integrin-mediated assembly of focal adhesions and actin stress fibres is rho-dependent. Cell Adhesion Com- mun. In press

Bates RC, Buret A, van Helden DF, Horton MA, Burns GF. 1994. Apoptosis induced by inhibiton of intercellular contact. J. Cell Biol. 125:403-15

Baudoin C, van der Flier A, Borradori L, Sonnenberg A. 1996. Genomic organization of the mouse $\beta 1 \mathrm{D}$ gene: conservation of the $\beta 1 \mathrm{D}$ but not of the $\beta 1 \mathrm{~B}$ and $\beta 1 \mathrm{C}$ integrin splice variants. Cell Adhesion Commun. In press

Beckerle MC. 1986. Identification of a new protein localized at sites of cell-substrate adhesion. J. Cell Biol. 103:1679-87

Beckerle MC, Burridge K, DeMartino GN, Croall DE. 1987. Colocalization of calciumdependent protease II and one of its substrates at sites of cell adhesion. Cell 51:569-77

Belkin AM, Burridge K. 1995. Localization of utrophin and aciculin at sites of cell-matrix and cell-cell adhesion in cultured cells. Exp. Cell. Res. 221:132-40

Belkin AM, Klimanskaya IV, Lukashev ME, Lilley K, Critchley DR, Koteliansky VE. 1994. A novel phosphoglucomutase-related protein is concentrated in adherens junctions of muscle and nonmuscle cells. J. Cell Sci. 107:159-73

Belkin AM, Koteliansky VE. 1987. Interaction of iodinated vinculin, metavinculin and $\alpha$ actinin with cytoskeletal proteins. FEBS Lett. 220:291-94

Belkin AM, Smalheiser NR. 1996. Localization of cranin (dystroglycan) at sites of cell-matrix and cell-cell contact: recruitment to focal adhesions is dependent upon extracellular ligands. Cell Adhesion Commun. In press

Belkin AM, Zhidkova NI, Balzac F, Altruda F, Tomatis D, et al. 1996. Beta-1D integrin displaces the beta-1A isoform in striated muscles-localization at junctional structures and signaling potential in nonmuscle cells. J. Cell Biol. 132:211-26

Bellis SL, Miller JT, Turner CE. 1995. Characterization of tyrosine phosphorylation of paxillin in vitro by focal adhesion kinase. J. Biol. Chem. 270:17437-41

Benecke BJ, Ben-Ze'ev A, Penman S. 1978. The control of mRNA production, translation and turnover in suspended and reattached anchorage-dependent fibroblasts. Cell 14:931-39

Benecke BJ, Ben-Ze'ev A, Penman S. 1980. The regulation of RNA metabolism in suspended and reattached anchorage-dependent 3T6 fibroblasts. J. Cell. Physiol. 103:247-54

Ben-Ze'ev A, Farmer SR, Penman S. 1980. 
Protein synthesis requires cell-surface contact while nuclear events respond to cell shape in anchorage-dependent fibroblasts. Cell 21:365-72

Bergman M, Joukov V, Virtanen I, Alitalo K. 1995. Overexpressed Csk tyrosine kinase is localized in focal adhesions, causes reorganization of $\alpha_{\mathrm{v}} \beta_{5}$ integrin, and interferes with HeLa cell spreading. Mol. Cell. Biol. 15:71122

Berridge MJ. 1993. Inositol trisphosphate and calcium signaling. Nature 361:315-25

Beyth RJ, Culp LA. 1984. Complementary adhesive responses of human skin fibroblasts to the cell-binding domain of fibronectin and the heparin sulfate-binding protein, platelet factor-4. Exp. Cell. Res. 155:537-48

Birge RB, Fajardo JE, Mayer BJ, Hanafusa H. 1992. Tyrosine-phosphorylated epidermal growth factor receptor and cellular p130 provide high affinity binding substrates to analyze Crk-phosphotyrosine-dependent interactions in vitro. J. Biol. Chem. 267:10588-95

Birge RB, Fajardo JE, Reichman C, Shoelson SE, Songyang Z, et al. 1993. Identification and characterization of a highaffinity interaction between $\mathrm{v}$-Crk and tyrosine-phosphorylated paxillin in CT10transformed fibroblasts. Mol. Cell. Biol. 13:4648-56

Bockholt SM, Burridge K. 1993. Cell spreading on extracellular matrix proteins induces tyrosine phosphorylation of tensin. J. Biol. Chem. 268:14565-67

Bockholt SM, Burridge K. 1995. An examination of focal adhesion formation and tyrosine phosphorylation in fibroblasts isolated from src(-), fyn(-), and yes(-) mice. Cell Adhes. Commun. 3:91-100

Bockholt SM, Otey CA, Glenney JR Jr, Burridge K. 1992. Localization of a $215-\mathrm{kDa}$ tyrosine-phosphorylated protein that crossreacts with tensin antibodies. Exp. Cell. Res. 203:39-46

Bohmer RM, Scharf E, Assoian RK. 1996. Cytoskeletal integrity is required throughout the mitogen stimulation phase of the cell cycle and mediates the anchorage-dependent expression of cyclin D1. Mol. Biol. Cell 7:10111

Boudreau N, Sympson CJ, Werb Z, Bissell MJ. 1995. Suppression of ICE and apoptosis in mammary epithelial cells by extracellular matrix. Science 267:891-93

Bretscher A. 1981. Fimbrin is a cytoskeletal protein that crosslinks F-actin in vitro. Proc. Natl. Acad. Sci. USA 78:6849-53

Briesewitz R, Kern A, Marcantonio EE. 1993. Ligand-dependent and -independent integrin focal contact localization: the role of the $\alpha$ chain cytoplasmic domain. Mol. Biol. Cell 4:593-604

Briesewitz R, Kern A, Marcantonio EE. 1995. Assembly and function of integrin receptors is dependent on opposing $\alpha$ and $\beta$ cytoplasmic domains. Mol. Biol. Cell 6:997-1010

Brooks PC, Montgomery AM, Rosenfeld M, Reisfeld RA, Hu T, et al. 1994. Integrin $\alpha_{\mathrm{v}} \beta_{3}$ antagonists promote tumor regression by inducing apoptosis of angiogenic blood vessels. Cell 79:1157-64

Buhl AM, Johnson NL, Dhanasekaran N, Johnson GL. 1995. G alpha 12 and $G$ alpha 13 stimulate Rho-dependent stress fiber formation and focal adhesion assembly. J. Biol. Chem. 270:24631-34

Burbelo PD, Miyamoto S, Utani A, Brill S, Yamada KM, et al. 1995. P190-B, a new member of the rhoGAP family, and rho are induced to cluster after integrin cross-linking. J. Biol. Chem. 270:30919-26

Burridge K. 1981. Are stress fibres contractile? Nature 294:691-92

Burridge K, Connell L. 1983. A new protein of adhesion plaques and ruffling membranes. $J$. Cell Biol. 97:359-67

Burridge K, Fath K, Kelly T, Nuckolls G, Turner C. 1988. Focal adhesions: transmembrane junctions between the extracellular matrix and the cytoskeleton. Annu. Rev. Cell Biol. $4: 487-525$

Burridge K, Feramisco JR. 1980. Microinjection and localization of a $130 \mathrm{~K}$ protein in living fibroblasts: a relationship to actin and fibronectin. Cell 19:587-95

Burridge K, Mangeat P. 1984. An interaction between vinculin and talin. Nature 308:74446

Burridge K, Turner CE, Romer LH. 1992. Tyrosine phosphorylation of paxillin and pp125 $5^{\text {FAK }}$ accompanies cell adhesion to extracellular matrix: a role in cytoskeletal assembly. J. Cell Biol. 119:893-903

Buss F, Temm-Grove C, Henning S, Jockusch BM. 1992. Distribution of profilin in fibroblasts correlates with the presence of highly dynamic actin filaments. Cell Motil. Cytoskelet. 22:51-61

Buxbaum RE, Heidemann SR. 1988. A thermodynamic model for force integration and microtubule assembly during axonal elongation. J. Theor. Biol. 134:379-90

Calalb MB, Polte TR, Hanks SK. 1995. Tyrosine phosphorylation of focal adhesion kinase at sites in the catalytic domain regulates kinase activity: a role for Src family kinases. Mol. Cell. Biol. 15:954-63

Cattelino A, Longhi R, de Curtis I. 1995. Differential distribution of two cytoplasmic variants of the $\alpha_{6} \beta_{1}$ integrin laminin receptor in 
the ventral plasma membrane of embryonic fibroblasts. J. Cell Sci. 108:3067-78

Chakraborty T, Ebel F, Domann E, Niebuhr K, Gerstel B, et al. 1995. A focal adhesion factor directly linking intracellularly motile Listeria monocytogenes and Listeria ivanovii to the actin-based cytoskeleton of mammalian cells. EMBO J. 14:131421

Chardin P, Boquet P, Madaule P, Popoff MR, Rubin EJ, Gill DM. 1989. The mammalian G protein rhoC is ADP-ribosylated by Clostridium botulinum exoenzyme $\mathrm{C} 3$ and affects actin microfilaments in Vero cells. EMBO J. 8:1087-92

Chen HC, Appeddu PA, Parsons JT, Hildebrand JD, Schaller MD, Guan JL. 1995. Interaction of focal adhesion kinase with cytoskeletal protein talin. J. Biol. Chem. 270:16995-99

Chen HC, Guan JL. 1994a. Stimulation of phosphatidylinositol $3^{\prime}$-kinase association with focal adhesion kinase by platelet-derived growth factor. J. Biol. Chem. 269:31229-33

Chen HC, Guan JL. 1994b. Association of focal adhesion kinase with its potential substrate phosphatidylinositol 3-kinase. Proc. Natl. Acad. Sci. USA 91:10148-52

Chen Q, Kinch MS, Lin TH, Burridge K, Juliano RL. 1994. Integrin-mediated cell adhesion activates mitogen-activated protein $\mathrm{ki}$ nases. J. Biol. Chem. 269:26602-5

Chen WT, Singer SJ. 1982. Immunoelectron microscopic studies of the sites of cellsubstratum and cell-cell contacts in cultured fibroblasts. J. Cell Biol. 95:205-22

Chong LD, Traynor-Kaplan A, Bokoch GM, Schwartz MA. 1994. The small GTP-binding protein Rho regulates a phosphatidylinositol 4-phosphate 5-kinase in mammalian cells. Cell 79:507-13

Chrzanowska-Wodnicka M, Burridge K. 1994. Tyrosine phosphorylation is involved in reorganization of the actin cytoskeleton in response to serum or LPA stimulation. J. Cell Sci. 107:3643-54

Chrzanowska-Wodnicka M, Burridge K. 1996. Rho-stimulated contractility drives the formation of stress fibers and focal adhesions. J. Cell Biol. 133:1403-15

Cichowski K, Brugge JS, Brass LF. 1996. Thrombin receptor activation and integrin engagement stimulate tyrosine phosphorylation of the proto-oncogene product, $\mathrm{p} 95^{\mathrm{Vav}}$, in platelets. J. Biol. Chem. 271:7544-50

Chun JS, Jacobson BS. 1992. Spreading of HeLa cells on a collagen substratum requires a second messenger formed by the lipoxygenase metabolism of arachidonic acid released by collagen receptor clustering. Mol. Biol. Cell 3:481-92
Chun JS, Jacobson BS. 1993. Requirement for diacylglycerol and protein kinase $\mathrm{C}$ in $\mathrm{HeLa}$ cell-substratum adhesion and their feedback amplification of arachidonic acid production for optimum cell spreading. Mol. Biol. Cell 4:271-81

Citi S, Kendrick-Jones J. 1986. Regulation in vitro of brush border myosin by light chain phosphorylation. J. Mol. Biol. 188:369-82

Clark EA, Brugge JS. 1995. Integrins and signal transduction pathways: the road taken. Science 268:233-39

Cobb BS, Schaller MD, Leu TH, Parsons JT. 1994. Stable association of pp60 $0^{\mathrm{src}}$ and pp5 $9^{\text {fyn }}$ with the focal adhesion-associated protein tyrosine kinase, pp $125^{\mathrm{FAK}}$. Mol. Cell. Biol. 14:147-55

Cooper JA, Howell B. 1993. The when and how of Src regulation. Cell 73:1051-54

Coso OA, Chiariello M, Yu JC, Teramoto $\mathrm{H}$, Crespo P, et al. 1995. The small GTP-binding proteins $\mathrm{Rac} 1$ and $\mathrm{Cdc} 42$ regulate the activity of the JNK/SAPK signaling pathway. Cell 81:1137-46

Craig R, Smith R, Kendrick-Jones J. 1983. Light-chain phosphorylation controls the conformation of vertebrate non-muscle and smooth muscle myosin molecules. Nature 302:436-39

Cramer LP, Mitchison TJ. 1995. Myosin is involved in postmitotic cell spreading. J. Cell Biol. 131:179-89

Crawford AW, Michelsen JW, Beckerle MC. 1992. An interaction between zyxin and $\alpha$ actinin. J. Cell Biol. 116:1381-93

Crawford AW, Pino JD, Beckerle MC. 1994. Biochemical and molecular characterization of the chicken cysteine-rich protein, a developmentally regulated LIM-domain protein that is associated with the actin cytoskeleton. J. Cell Biol. 124:117-27

Crowley E, Horwitz AF. 1995. Tyrosine phosphorylation and cytoskeletal tension regulate the release of fibroblast adhesions. J. Cell Biol. 131:525-37

Danowski BA. 1989. Fibroblast contractility and actin organization are stimulated by microtubule inhibitors. J. Cell Sci. 93:255-66

Defilippi P, Bozzo C, Volpe G, Romano G, Venturino M, et al. 1994. Integrin-mediated signal transduction in human endothelial cells: analysis of tyrosine phosphorylation events. Cell Adhes. Commun. 2:75-86

Dejana E, Colella S, Conforti G, Abbadini M, Gaboli M, Marchisio PC. 1988. Fibronectin and vitronectin regulate the organization of their respective Arg-Gly-Asp adhesion receptors in cultured human endothelial cells. $J$. Cell Biol. 107:1215-23

DePasquale JA, Izzard CS. 1987. Evidence for 
an actin-containing cytoplasmic precursor of the focal contact and the timing of incorporation of vinculin at the focal contact. J. Cell Biol. 105:2803-9

DePasquale JA, Izzard CS. 1991. Accumulation of talin in nodes at the edge of the lamellipodium and separate incorporation into adhesion plaques at focal contacts in fibroblasts. J. Cell Biol. 113:1351-59

Douville PJ, Harvey WJ, Carbonetto S. 1988. Isolation and partial characterization of high affinity laminin receptors in neural cells. $J$. Biol. Chem. 263:14964-69

Ervasti JM, Campbell KP. 1993a. Dystrophin and the membrane skeleton. Curr. Opin. Cell Biol. 5:82-87

Ervasti JM, Campbell KP. 1993b. A role for the dystrophin-glycoprotein complex as a transmembrane linker between laminin and actin. J. Cell Biol. 122:809-23

Evans RR, Robson RM, Stromer MH. 1984. Properties of smooth muscle vinculin. J. Biol. Chem. 259:3916-24

Farmer SR, Ben-Ze'ev A, Benecke BJ, Penman S. 1978. Altered translatability of messenger RNA from suspended anchorage-dependent fibroblasts: Reversal upon cell attachment to a surface. Cell 15:931-39

Fath KR, Edgell CJ, Burridge K. 1989. The distribution of distinct integrins in focal contacts is determined by the substratum composition. J. Cell Sci. 92:67-75

Feramisco JR. 1979. Microinjection of fluorescently labeled $\alpha$-actinin into living fibroblasts. Proc. Natl. Acad. Sci. USA 76:3967-71

Fernandez A, Brautigan DL, Mumby M, Lamb NJ. 1990. Protein phosphatase type-1, not type-2A, modulates actin microfilament integrity and myosin light chain phosphorylation in living nonmuscle cells. J. Cell Biol. 111:103-12

Ferrell JE, Martin GS. 1989. Tyrosine-specific phosphorylation is regulated by glycoprotein IIb/IIIa in platelets. Proc. Natl. Acad. Sci. USA 86:2234-38

Fincham VJ, Wyke JA, Frame MC. 1995. vSrc-induced degradation of focal adhesion kinase during morphological transformation of chicken embryo fibroblasts. Oncogene 10:2247-52

Fleischer M, Wohlfarth-Bottermann KE. 1975. Correlation between tension force generation, fibrillogenesis and ultrastructure of cytoplasmic actomyosin during isometric and isotonic contractions of protoplasmic strands. Cytobiologie 10:339-65

Fornaro M, Zheng DQ, Languino LR. 1995. The novel structural motif Gln795-Gln802 in the integrin beta $1 \mathrm{C}$ cytoplasmic domain regulates cell proliferation. J. Biol. Chem.
270:24666-69

Franke RP, Grafe M, Schnittler H, Seiffge D, Mittermayer C, Drenckhahn D. 1984. Induction of human vascular endothelial stress fibres by fluid shear stress. Nature 307:648-49

Frisch SM, Francis H. 1994. Disruption of epithelial cell-matrix interactions induces apoptosis. J. Cell Biol. 124:619-26

Frisch SM, Vuori K, Ruoslahti E. 1996. Control of adhesion-dependent cell survival by focal adhesion kinase. J. Cell Biol. In press

Fukami K, Endo T, Imamura M, Takenawa T. 1994. $\alpha$-Actinin and vinculin are PIP $_{2}-$ binding proteins involved in signaling by tyrosine kinase. J. Biol. Chem. 269:1518-22

Fukami K, Furuhashi K, Inagaki M, Endo T, Hatano S, Takenawa T. 1992. Requirement of phosphatidylinositol 4,5-bisphosphate for $\alpha$-actinin function. Nature 359:150-52

Fukui Y, Hanafusa H. 1989. Phosphatidylinositol kinase activity associates with viral $\mathrm{p} 60^{\mathrm{src}}$ protein. Mol. Cell. Biol. 9:1651-58

Gabbiani G, Majno G, Ryan GB. 1973. The fibroblast as a contractile cell: the myofibroblast. In Biology of Fibroblast, ed. E Kulonen, J Pikkarainen, pp. 139-54. New York: Academic

Gallagher PJ, Garcia JGN, Herring BP. 1995. Expression of a novel myosin light chain kinase in embryonic tissues and cultured cells. J. Biol. Chem. 270:29090-95

Gee SH, Blacher RW, Douville PJ, Provost PR, Yurchenco PD, Carbonetto S. 1993. Lamininbinding protein 120 from brain is closely related to the dystrophin-associated glycoprotein, dystroglycan, and binds with high affinity to the major heparin binding domain of laminin. J. Biol. Chem. 268:14972-80

Geiger B. 1979. A $130 \mathrm{~K}$ protein from chicken gizzard: its localization at the termini of microfilament bundles in cultured chicken cells. Cell 18:193-205

Geiger B, Ayalon O, Ginsberg D, Volberg T, Rodriguez Fernandez JL, et al. 1992a. Cytoplasmic control of cell adhesion. Cold Spring Harbor Symp. Quant. Biol. 57:631-42

Geiger B, Salomon D, Takeichi M, Hynes RO. 1992b. A chimeric N-cadherin/beta 1integrin receptor which localizes to both cellcell and cell-matrix adhesions. J. Cell Sci. 103:943-51

Giancotti FG, Ruoslahti E. 1990. Elevated levels of the $\alpha_{5} \beta_{1}$ fibronectin receptor suppress the transformed phenotype of Chinese hamster ovary cells. Cell 60:849-59

Gilmore AP, Burridge K. 1996. Regulation of vinculin binding to talin and actin by phosphatidylinositol-4-5-bisphosphate. $\mathrm{Na}$ ture. 381:531-35

Gilmore AP, Romer LH. 1996. Inhibition of 
FAK signalling in focal adhesions decreases cell motility and proliferation. Mol. Biol. Cell. 7:1209-24

Ginsberg MH, Xiaoping D, O'Toole TE, Loftus JC, Plow EF. 1993. Platelet integrins. Thromb. Haemost. 70:87-93

Giuliano KA, Taylor DL. 1990. Formation, transport, contraction, and disassembly of stress fibers in fibroblasts. Cell Motil. Cytoskelet. 16:14-21

Gluck U, Ben-Ze'ev A. 1994. Modulation of $\alpha$-actinin levels affects cell motility and confers tumorigenicity on 3T3 cells. J. Cell Sci. 107:1773-82

Gluck U, Kwiatkowski DJ, Ben-Ze'ev A. 1993. Suppression of tumorigenicity in simian virus 40-transformed 3T3 cells transfected with $\alpha$ actinin cDNA. Proc. Natl. Acad. Sci. USA 90:383-87

Goeckeler ZM, Wysolmerski RB. 1995. Myosin light chain kinase-regulated endothelial cell contraction: the relationship between isometric tension, actin polymerization, and myosin phosphorylation. J. Cell Biol. 130:613-27

Golden A, Brugge JS. 1989. Thrombin treatment induces rapid changes in tyrosine phosphorylation in platelets. Proc. Natl. Acad. Sci. USA 86:901-5

Gong MC, Fuglsang A, Alessi D, Kobayashi S, Cohen P, et al. 1992. Arachidonic acid inhibits myosin light chain phosphatase and sensitizes smooth muscle to calcium. J. Biol. Chem. 267:21492-98

Gordon WE. 1978. Immunofluorescent and ultrastructural studies of "sarcomeric" units in stress fibers of cultured non-muscle cells. Exp. Cell. Res. 117:253-60

Grinnell F. 1994. Fibroblasts, myofibroblasts, and wound contraction. J. Cell Biol. 124:4014

Guan JL, Shalloway D. 1992. Regulation of focal adhesion-associated protein tyrosine kinase by both cellular adhesion and oncogenic transformation. Nature 358:690-92

Guan JL, Trevithick JE, Hynes RO. 1991. Fibronectin/integrin interaction induces tyrosine phosphorylation of a $120-\mathrm{kDa}$ protein. Cell Regul. 2:951-64

Guinebault C, Payrastre B, Racaud-Sultan C, Mazarguil H, Breton M, et al. 1995. Integrindependent translocation of phosphoinositide 3-kinase to the cytoskeleton of thrombinactivated platelets involves specific interactions of p85alpha with actin filaments and focal adhesion kinase. J. Cell Biol. 129(3):83142

Gulbins E, Coggeshall KM, Baier G, Katzav S, Burn P, Altman A. 1993. Tyrosine kinasestimulated guanine nucleotide exchange ac- tivity of Vav in $\mathrm{T}$ cell activation. Science 260:822-25

Haffner C, Jarchau T, Reinhard M, Hoppe J, Lohmann SM, Walter U. 1995. Molecular cloning, structural analysis and functional expression of the proline-rich focal adhesion and microfilament-associated protein VASP. EMBO J. 14:19-27

Haimovich B, Lipfert L, Brugge JS, Shattil SJ. 1993. Tyrosine phosphorylation and cytoskeletal reorganization in platelets are triggered by interaction of integrin receptors with their immobilized ligands. J. Biol. Chem. 268:15868-77

Halbrugge M, Walter U. 1989. Purification of a vasodilator-regulated phosphoprotein from human platelets. Eur. J. Biochem. 185:41-50

Hall A. 1994. Small GTP-binding proteins and the regulation of the actin cytoskeleton. Anпи. Rev. Cell Biol. 10:31-54

Halliday NL, Tomasek JJ. 1995. Mechanical properties of the extracellular matrix influence fibronectin fibril assembly in vitro. Exp. Cell. Res. 217:109-17

Hanks SK, Calalb MB, Harper MC, Patel SK. 1992. Focal adhesion protein-tyrosine kinase phosphorylated in response to cell attachment to fibronectin. Proc. Natl. Acad. Sci. USA 89:8487-91

Hannigan GE, Leunghagesteijn C, Fitzgibbon L, Coppolino MG, Radeva G, et al. 1996. Regulation of cell adhesion and anchoragedependent growth by a new $\beta_{1}$-integrinlinked protein kinase. Nature 379:91-96

Hansen CA, Schroering AG, Carey DJ, Robishaw JD. 1994. Localization of a heterotrimeric $\mathrm{G}$ protein gamma subunit to focal adhesions and associated stress fibers. J. Cell Biol. 126:811-19

Harris AK, Wild P, Stopak D. 1980. Silicone rubber substrata: a new wrinkle in the study of cell locomotion. Science 208:177-79

Hayashi Y, Haimovich B, Reszka A, Boettiger D, Horwitz A. 1990. Expression and function of chicken integrin 1 subunit and its cytoplasmic domain mutants in mouse NIH 3 T3 cells. J. Cell Biol. 110:175-84

Heath JP, Dunn GA. 1978. Cell to substratum contacts of chick fibroblasts and their relation to the microfilament system. A correlated interference-reflection and highvoltage electron-microscope study. J. Cell Sci. 29:197-212

Hemler ME, Weitzman JB, Pasqualini R, Kawaguchi S, Kassner PD, Bertichevsky FB. 1994. Structure, biochemical properties and biological functions of integrin cytoplasmic domain. In Integrins: The Biological Problem, pp. 242-56. Boca Raton, FL: CRC Press Henske EP, Short MP, Jozwiak S, Bovey CM, 
Ramlakhan S, et al. 1995. Identification of VAV2 on 9q34 and its exclusion as the tuberous sclerosis gene TSC1. Ann. Hum. Genet. 59:25-37

Higuchi H, Takemori S. 1989. Butanedione monoxime suppresses contraction and ATPase activity of rabbit skeletal muscle. $J$. Biochem. 105:638-43

Hildebrand JD, Schaller MD, Parsons JT. 1993. Identification of sequences required for the efficient localization of the focal adhesion $\mathrm{ki}$ nase, pp $125^{\mathrm{FAK}}$, to cellular focal adhesions. $J$. Cell Biol. 123:993-1005

Hildebrand JD, Schaller MD, Parsons JT. 1995. Paxillin, a tyrosine phosphorylated focal adhesion-associated protein binds to the carboxyl terminal domain of focal adhesion kinase. Mol. Biol. Cell 6:637-47

Hill CS, Wynne J, Treisman R. 1995. The Rho family GTPases RhoA, Rac1, and CDC42Hs regulate transcriptional activation by SRF. Cell 81:1159-70

Hirata K, Kikuchi A, Sasaki T, Kuroda S, Kaibuchi K, et al. 1992. Involvement of rho p21 in the GTP-enhanced calcium ion sensitivity of smooth muscle contraction. J. Biol. Chem. 267:8719-22

Honer B, Citi S, Kendrick-Jones J, Jockusch BM. 1988. Modulation of cellular morphology and locomotory activity by antibodies against myosin. J. Cell Biol. 107:2181-89

Hordijk PL, Verlaan I, van Corven EJ, Moolenaar WH. 1994. Protein tyrosine phosphorylation induced by lysophosphatidic acid in Rat-1 fibroblasts. Evidence that phosphorylation of map kinase is mediated by the Gip21ras pathway. J. Biol. Chem. 269:645-51

Horwitz A, Duggan K, Buck C, Beckerle MC, Burridge K. 1986. Interaction of plasma membrane fibronectin receptor with talin - a transmembrane linkage. Nature 320:531-33

Hotchin NA, Hall A. 1995. The assembly of integrin adhesion complexes requires both extracellular matrix and intracellular rho/rac GTPases. J. Cell Biol. 131:1857-65

Hynes RO. 1992. Integrins: versatility, modulation, and signaling in cell adhesion. Cell 69:11-25

Ibraghimov-Beskrovnaya O, Ervasti JM, Leveille CJ, Slaughter CA, Sernett SW, Campbell KP. 1992. Primary structure of dystrophinassociated glycoproteins linking dystrophin to the extracellular matrix. Nature 355:696702

Ibraghimov-Beskrovnaya O, Milatovich A, Ozcelik T, Yang B, Koepnick K, et al. 1993. Human dystroglycan: skeletal muscle cDNA, genomic structure, origin of tissue specific isoforms and chromosomal localization. Hum. Mol. Genet. 2:1651-57
Ichikawa K, Ito M, Hartshorne DJ. 1996. Phosphorylation of the large subunit of myosin phosphatase and inhibition of phosphatase activity. J. Biol. Chem. 271:4733-40

Ikebe M, Koretz J, Hartshorne DJ. 1988. Effects of phosphorylation of light chain residues threonine 18 and serine 19 on the properties and conformation of smooth muscle myosin. J. Biol. Chem. 263:6432-37

Ikebe M. 1989. Phosphorylation of a second site for myosin light chain kinase on platelet myosin. Biochemistry 28:8750-55

Ikebe M, Reardon S. 1990. Phosphorylation of bovine platelet myosin by protein kinase $\mathrm{C}$. Biochemistry 29:2713-20

Ilic D, Furuta Y, Kanazawa S, Takeda N, Sobue K, et al. 1995. Reduced cell motility and enhanced focal contact formation in cells from FAK-deficient mice. Nature 377:539-44

Ingber DE. 1993. Cellular tensegrity: defining new rules of biological design that govern the cytoskeleton. J. Cell Sci. 104:613-27

Ingber DE, Prusty D, Frangioni JV, Cragoe EJ Jr, Lechene C, Schwartz MA. 1990. Control of intracellular $\mathrm{pH}$ and growth by fibronectin in capillary endothelial cells. J. Cell Biol. 110:1803-11

Isenberg G. 1991. Actin binding proteinslipid interactions. J. Muscle Res. Cell Motil. 12:136-44

Isenberg G, Rathke PC, Hulsmann N, Franke WW, Wohlfarth-Bottermann KE. 1976. Cytoplasmic actomyosin fibrils in tissue culture cells: direct proof of contractility by visualization of ATP-induced contraction in fibrils isolated by laser micro-beam dissection. Cell Tissue Res. 166:427-43

Ishikawa R, Yamashiro S, Matsumura F. 1989a. Differential modulation of actin-severing activity of gelsolin by multiple isoforms of cultured rat cell tropomyosin. Potentiation of protective ability of tropomyosins by 83 kDa nonmuscle caldesmon. J. Biol. Chem. 264:7490-97

Ishikawa R, Yamashiro S, Matsumura F. 1989b. Annealing of gelsolin-severed actin fragments by tropomyosin in the presence of $\mathrm{Ca}^{2+}$. Potentiation of the annealing process by caldesmon. J. Biol. Chem. 264:16764-70

Ishizaki T, Maekawa M, Fujisawa K, Okawa K, Iwamatsu A, et al. 1996. The small GTPbinding protein Rho binds to and activates a $160 \mathrm{kDa}$ Ser/Thr protein kinase homologous to myotonic dystrophy kinase. $E M B O$ J. 15:1885-93

Izzard CS, Radinsky R, Culp LA. 1986. Substratum contacts and cytoskeletal reorganization of $\mathrm{BALB} / \mathrm{c} 3 \mathrm{~T} 3$ cells on a cell-binding fragment and heparin-binding fragments of plasma fibronectin. Exp. Cell. Res. 165:320 
36

Jaken S, Leach K, Klauck T. 1989. Association of type 3 protein kinase $\mathrm{C}$ with focal contacts in rat embryo fibroblasts. J. Cell Biol. 109:697-704

Jalink K, Moolenaar WH. 1992. Thrombin receptor activation causes rapid neural cell rounding and neurite retraction independent of classic second messengers. J. Cell Biol. 118:411-19

Jalink K, van Corven EJ, Hengeveld T, Morii N, Narumiya S, Moolenaar WH. 1994. Inhibition of lysophosphatidate- and thrombininduced neurite retraction and neuronal cell rounding by ADP ribosylation of the small GTP-binding protein Rho. J. Cell Biol. 126: 801-10

Janmey PA, Stossel TP. 1987. Modulation of gelsolin function by phosphatidylinositol 4,5-bisphosphate. Nature 325:362-64

Jockusch BM, Bubeck P, Giehl K, Kroemker M, Moschner J, et al. 1995. The molecular architecture of focal adhesions. Annu. Rev. Cell Dev. Biol. 11:379-416

Johnson RP, Craig SW. 1994. An intramolecular association between the head and tail domains of vinculin modulates talin binding. $J$. Biol. Chem. 269:12611-19

Johnson RP, Craig SW. 1995a. F-actin binding site masked by the intramolecular association of vinculin head and tail domains. Nature 373:261-64

Johnson RP, Craig SW. 1995b. The carboxyterminal tail domain of vinculin contains a cryptic binding site for acidic phospholipids. Biochem. Biophys. Res. Commun. 210:15964

Juliano RL, Haskill S. 1993. Signal transduction from the extracellular matrix. J. Cell Biol. 120:577-85

Kaplan KB, Bibbins KB, Swedlow JR, Arnaud M, Morgan DO, Varmus HE. 1994. Association of the amino-terminal half of c-Src with focal adhesions alters their properties and is regulated by phosphorylation of tyrosine 527 . EMBO J. 13:4745-56

Kaplan KB, Swedlow JR, Morgan DO, Varmus HE. 1995. c-Src enhances the spreading of src-/-fibroblasts on fibronectin by a kinase-independent mechanism. Genes Dev. 9:1505-17

Kapron-Bras C, Fitz-Gibbon L, Jeevaratnam P, Wilkins J, Dedhar S. 1993. Stimulation of tyrosine phosphorylation and accumulation of GTP-bound p21ras upon antibody-mediated $\alpha_{2} \beta_{1}$ integrin activation in T-lymphoblastic cells. J. Biol. Chem. 268:20701-4

Kaufmann S, Piekenbrock T, Goldmann WH, Barmann M, Isenberg G. 1991. Talin binds to actin and promotes filament nucleation.
FEBS Lett. 284:187-91

Khosravi-Far R, Chrzanowska-Wodnicka M, Solski PA, Eva A, Burridge K, Der CJ. 1994. Dbl and Vav mediate transformation via mitogen-activated protein kinase pathways that are distinct from those activated by oncogenic Ras. Mol. Cell. Biol. 14:6848-57

Kimura K, Ito M, Amano M, Chihara K, Fukata Y, et al. 1996. Regulation of myosin phosphatase by Rho and Rho-associated kinase (Rho-kinase). Science 273:245-48

Kishi K, Sasaki T, Kuroda S, Itoh T, Takai Y. 1993. Regulation of cytoplasmic division of Xenopus embryo by rho $\mathrm{p} 21$ and its inhibitory GDP/GTP exchange protein (rho GDI). $J$. Cell Biol. 120:1187-95

Kitazawa T, Masuo M, Somlyo AP. 1991. G protein-mediated inhibition of myosin lightchain phosphatase in vascular smooth muscle. Proc. Natl. Acad. Sci. USA 88:9307-10

Kokubu N, Satoh M, Takayanagi I. 1995. Involvement of botulinum C3-sensitive GTPbinding proteins in $\alpha 1$-adrenoceptor subtypes mediating $\mathrm{Ca}(2+)$-sensitization. Eur. $J$. Pharmacol. 290:19-27

Kolega J. 1986. Effects of mechanical tension on protrusive activity and microfilament and intermediate filament organization in an epidermal epithelium moving in culture. $J$. Cell Biol. 102:1400-11

Kolodney MS, Elson EL. 1993. Correlation of myosin light chain phosphorylation with isometric contraction of fibroblasts. J. Biol. Chem. 268:23850-55

Kolodney MS, Elson EL. 1995. Contraction due to microtubule disruption is associated with increased phosphorylation of myosin regulatory light chain. Proc. Natl. Acad. Sci. USA 92:10252-56

Kornberg L, Earp HS, Parsons JT, Schaller M, Juliano RL. 1992. Cell adhesion or integrin clustering increases phosphorylation of a focal adhesion-associated tyrosine kinase. $J$. Biol. Chem. 267:23439-42

Kornberg LJ, Earp HS, Turner CE, Prockop C, Juliano RL. 1991. Signal transduction by integrins: increased protein tyrosine phosphorylation caused by clustering of beta 1 integrins. Proc. Natl. Acad. Sci. USA 88:8392-96

Kramarcy NR, Sealock R. 1990. Dystrophin as a focal adhesion protein. Colocalization with talin and the $M_{\mathrm{r}} 48,000$ sarcolemmal protein in cultured Xenopus muscle. FEBS Lett. 274:171-74

Kreis TE, Birchmeier W. 1980. Stress fiber sarcomeres of fibroblasts are contractile. Cell 22:555-61

Kumagai N, Morii N, Fujisawa K, Nemoto Y, Narumiya S. 1993. ADP-ribosylation of rho p21 inhibits lysophosphatidic acid- 
induced protein tyrosine phosphorylation and phosphatidylinositol 3-kinase activation in cultured Swiss 3T3 cells. J. Biol. Chem. 268:24535-38

Lakonishok M, Muschler J, Horwitz AF. 1992. The $\alpha_{5} \beta_{1}$ integrin associates with a dystrophin-containing lattice during muscle development. Dev. Biol. 152:209-20

LaFlamme SE, Akiyama SK, Yamada KM. 1992. Regulation of fibronectin receptor distribution. J. Cell Biol. 117:437-47. Erratum. 1992. J. Cell Biol. 118(2):491

Lamb NJ, Fernandez A, Conti MA, Adelstein R, Glass DB, et al. 1988. Regulation of actin microfilament integrity in living nonmuscle cells by the cAMP-dependent protein kinase and the myosin light chain kinase. J. Cell Biol. 106:1955-71

Lancaster CA, Taylor-Harris PM, Self AJ, Brill S, van Erp HE, Hall A. 1994. Characterization of rhoGAP. A GTPase-activating protein for rho-related small GTPases. J. Biol. Chem. 269:1137-42

Languino LR, Ruoslahti E. 1992. An alternative form of the integrin beta 1 subunit with a variant cytoplasmic domain. J. Biol. Chem. 267:7116-20

Lassing I, Lindberg U. 1985. Specific interaction between phosphatidylinositol 4,5bisphosphate and profilactin. Nature 314:472-74

Laudanna C, Campbell JJ, Butcher EC. 1996. Role of rho in chemoattractant-activated leukocyte adhesion through integrins. Science 271:981-83

Lazarides E, Burridge K. 1975. Alpha-actinin: immunofluorescent localization of a muscle structural protein in nonmuscle cells. Cell 6:289-98

Leavesley DI, Schwartz MA, Rosenfeld M, Cheresh DA. 1993. Integrin beta 1- and beta 3 -mediated endothelial cell migration is triggered through distinct signaling mechanisms. J. Cell Biol. 121:163-70

Leung T, Manser E, Tan L, Lim L. 1995. A novel serine/threonine kinase binding the ras-related RhoA GTPase which translocates the kinase to peripheral membranes. J. Biol. Chem. 270:29051-54

Lev S, Moreno H, Martinez R, Canoll P, Peles E, et al. 1995. Protein tyrosine kinase Pyk2 involved in $\mathrm{Ca}^{2+}$-induced regulation of ion channel and MAP kinase functions. Nature 376:737-45

Lewis JM, Schwartz MA. 1995. Mapping in vivo associations of cytoplasmic proteins with integrin beta 1 cytoplasmic domain mutants. Mol. Biol. Cell 6:151-60

Lin YC, Grinnell F. 1993. Decreased level of PDGF-stimulated receptor autophosphoryla- tion by fibroblasts in mechanically relaxed collagen matrices. J. Cell Biol. 122:663-72

Lipfert L, Haimovich B, Schaller MD, Cobb BS, Parsons JT, Brugge JS. 1992. Integrindependent phosphorylation and activation of the protein tyrosine kinase $\mathrm{pp} 125^{\mathrm{FAK}}$ in platelets. J. Cell Biol. 119:905-12

Lo SH, Janmey PA, Hartwig JH, Chen LB. 1994. Interactions of tensin with actin and identification of its three distinct actin-binding domains. J. Cell Biol. 125:1067-75

Mabuchi I, Hamaguchi Y, Fujimoto H, Morii N, Mishima M, Narumiya S. 1993. A rho-like protein is involved in the organisation of the contractile ring in dividing sand dollar eggs. Zygote 1:325-31

Marcantonio EE, Guan JL, Trevithick JE, Hynes RO. 1990. Mapping of the functional determinants of the integrin beta 1 cytoplasmic domain by site-directed mutagenesis. Cell Regul. 1:597-604

Massia SP, Hubbell JA. 1991. An RGD spacing of $440 \mathrm{~nm}$ is sufficient for integrin $\alpha_{\mathrm{v}} \beta_{3^{-}}$ mediated fibroblast spreading and $140 \mathrm{~nm}$ for focal contact and stress fiber formation. $J$. Cell Biol. 114:1089-100

Matsuda M, Hashimoto Y, Muroya K, Hasegawa H, Kruata T. 1994. Crk protein binds to two guanine nucleotide-releasing proteins for the ras family and modulates nerve growth factor-induced activation of ras in PC12 cells. Mol. Cell Biol. 14:5495-500

Matsuguchi T, Inhorn RC, Carlesso N, Xu G, Druker B, Griffin JD. 1995. Tyrosine phosphorylation of p95 Vav in myeloid cells is regulated by GM-CSF, IL-3 and steel factor and is constitutively increased by p210BCR/ABL. EMBO J. 14:257-65

Matsumura F, Yamashiro S. 1993. Caldesmon. Curr. Opin. Cell Biol. 5:70-76

McKenna NM, Meigs JB, Wang YL. 1985. Exchangeability of $\alpha$-actinin in living cardiac fibroblasts and muscle cells. J. Cell Biol. 101:2223-32

McKillop DF, Fortune NS, Ranatunga KW, Geeves MA. 1994. The influence of 2,3butanedione 2-monoxime (BDM) on the interaction between actin and myosin in solution and in skinned muscle fibres. J. Muscle Res. Cell Motil. 15:309-18

McNamee HP, Ingber DE, Schwartz MA. 1993. Adhesion to fibronectin stimulates inositol lipid synthesis and enhances PDGFinduced inositol lipid breakdown. J. Cell Biol. 121:673-78

Menkel AR, Kroemker M, Bubeck P, Ronsiek M, Nikolai G, Jockusch BM. 1994. Characterization of an F-actin-binding domain in the cytoskeletal protein vinculin. J. Cell Biol. 126:1231-40 
Meredith J Jr, Takada Y, Fornaro M, Languino LR, Schwartz MA. 1995. Inhibition of cell cycle progression by the alternatively spliced integrin beta 1C. Science 269:1570-72

Meredith JE Jr, Fazeli B, Schwartz MA. 1993. The extracellular matrix as a cell survival factor. Mol. Biol. Cell 4:953-61

Minden A, Lin A, Claret FX, Abo A, Karin M. 1995. Selective activation of the JNK signaling cascade and c-Jun transcriptional activity by the small GTPases Rac and Cdc42Hs. Cell 81:1147-57

Mittal B, Sanger JM, Sanger JW. 1987. Binding and distribution of fluorescently labeled filamin in permeabilized and living cells. Cell. Motil. Cytoskelet. 8:345-59

Miyamoto S, Akiyama SK, Yamada KM. 1995a. Synergistic roles for receptor occupancy and aggregation in integrin transmembrane function. Science 267:883-85

Miyamoto S, Teramoto H, Coso OA, Gutkind JS, Burbelo PD, et al. 1995b. Integrin function: molecular hierarchies of cytoskeletal and signaling molecules. J. Cell Biol. 131:791-805

Mochitate K, Pawelek P, Grinnell F. 1991. Stress relaxation of contracted collagen gels: disruption of actin filament bundles, release of cell surface fibronectin, and down-regulation of DNA and protein synthesis. Exp. Cell. Res. 193:198-207

Montgomery AM, Reisfeld RA, Cheresh DA. 1994. Integrin $\alpha_{\mathrm{v}} \beta_{3}$ rescues melanoma cells from apoptosis in three-dimensional dermal collagen. Proc. Natl. Acad. Sci. USA 91:8856-60

Morii N, Teru-uchi T, Tominaga T, Kumagai N, Kozaki S, et al. 1992. A rho gene product in human blood platelets. II. Effects of the ADP-ribosylation by botulinum C3 ADPribosyltransferase on platelet aggregation. $J$. Biol. Chem. 267:20921-26

Morino N, Mimura T, Hamasaki K, Tobe K, Ueki K, et al. 1995. Matrix/integrin interaction activates the mitogen-activated protein kinase $\mathrm{p} 44^{\text {erk-1 }}$ and $\mathrm{p} 42^{\text {erk-2 }} . J$. Biol. Chem. 270:269-73

Muguruma M, Matsumura S, Fukazawa T. 1990. Direct interactions between talin and actin. Biochem. Biophys. Res. Commun. 171: 1217-23

Nada S, Okada M, Aizawa S, Nakagawa H. 1994. Identification of major tyrosinephosphorylated proteins in Csk-deficient cells. Oncogene 9:3571-78

Narumiya S, Sekine A, Fujiwara M. 1988. Substrate for botulinum ADP-ribosyltransferase, $\mathrm{Gb}$, has an amino acid sequence homologous to a putative rho gene product. J. Biol. Chem. 263:17255-57
Niggli V, Dimitrov DP, Brunner J, Burger MM. 1986. Interaction of the cytoskeletal component vinculin with bilayer structures analyzed with a photoactivatable phospholipid. J. Biol. Chem. 261:6912-18

Nishikawa M, de Lanerolle P, Lincoln TM, Adelstein RS. 1984. Phosphorylation of mammalian myosin light chain kinases by the catalytic subunit of cyclic AMP-dependent protein kinase and by cyclic GMP-dependent protein kinase. J. Biol. Chem. 259:8429-36

Nishiyama T, Sasaki T, Takaishi K, Kato M, Yaku H, et al. 1994. rac p21 is involved in insulin-induced membrane ruffling and rho p21 is involved in hepatocyte growth factor- and 12-O-tetradecanoylphorbol-13acetate (TPA)-induced membrane ruffling in KB cells. Mol. Cell. Biol. 14:2447-56

Nix DA, Beckerle MC. 1995. Inducible nuclear localization of the focal contact protein, zyxin. Mol. Biol. Cell 6:A63

Nobes CD, Hall A. 1995. Rho, rac, and cdc42 GTPases regulate the assembly of multimolecular focal complexes associated with actin stress fibers, lamellipodia, and filopodia. Cell 81:53-62

Nobes CD, Hawkins P, Stephens L, Hall A. 1995. Activation of the small GTP-binding proteins rho and rac by growth factor receptors. J. Cell. Sci. 108:225-33

Noda M, Yasuda-Fukazawa C, Moriishi K, Kato T, Okuda T, et al. 1995. Involvement of rho in GTPgammaS-induced enhancement of phosphorylation of $20 \mathrm{kDa}$ myosin light chain in vascular smooth muscle cells: inhibition of phosphatase activity. FEBS Lett. 367:246-50

Nojima Y, Morino N, Mimura T, Hamasaki K, Furuya H, et al. 1995. Integrin-mediated cell adhesion promotes tyrosine phosphorylation of p130Cas, a Src homology 3-containing molecule having multiple Src homolgy 2binding motifs. J. Biol. Chem. 270:15398402

Norman JC, Price LS, Ridley AJ, Hall A, Koffer A. 1994. Actin filament organization in activated mast cells is regulated by heterotrimeric and small GTP-binding proteins. J. Cell Biol. 126:1005-15

Nuckolls GH, Romer LH, Burridge K. 1992. Microinjection of antibodies against talin inhibits the spreading and migration of fibroblasts. J. Cell Sci. 102:753-62

Olson MF, Ashworth A, Hall A. 1995. An essential role for Rho, Rac, and Cdc42 GTPases in cell cycle progression through G1. Science 269:1270-72

Otey CA, Pavalko FM, Burridge K. 1990. An interaction between $\alpha$-actinin and the beta 1 integrin subunit in vitro. J. Cell Biol. 111:72129 
Otey CA, Vasquez GB, Burridge K, Erickson BW. 1993. Mapping of the $\alpha$-actinin binding site within the beta 1 integrin cytoplasmic domain. J. Biol. Chem. 268:21193-97

Otsuka H, Moskowitz M. 1975. Arrest of 3T3 cells in G1 phase in suspension culture. $J$. Cell. Physiol. 87:213-20

Otto JJ. 1986. The lack of interaction between vinculin and actin. Cell Motil. Cytoskelet. 6:48-55

Owens LV, Xu L, Craven RJ, Dent GA, Weiner TM, et al. 1995. Overexpression of the focal adhesion kinase (p125FAK) in invasive human tumors. Cancer Res. 55:2752-55

Paterson HF, Self AJ, Garrett MD, Just I, Aktories K, Hall A. 1990. Microinjection of recombinant p21rho induces rapid changes in cell morphology. J. Cell Biol. 111:1001-7

Pavalko FM, Burridge K. 1991. Disruption of the actin cytoskeleton after microinjection of proteolytic fragments of $\alpha$-actinin. J. Cell Biol. 114:481-91

Pavalko FM, LaRoche SM. 1993. Activation of human neutrophils induces an interaction between the integrin beta 2-subunit (CD18) and the actin binding protein $\alpha$-actinin. J. Immunol. 151:3795-807

Pavalko FM, Otey CA. 1994. Role of adhesion molecule cytoplasmic domains in mediating interactions with the cytoskeleton. Proc. Soc. Exp. Biol. Med. 205:282-93

Pavalko FM, Otey CA, Burridge K. 1989. Identification of a filamin isoform enriched at the ends of stress fibers in chicken embryo fibroblasts. J. Cell Sci. 94:109-18

Pavalko FM, Schneider G, Burridge K, Lim SS. 1995. Immunodetection of $\alpha$-actinin in focal adhesions is limited by antibody inaccessibility. Exp. Cell. Res. 217:534-40

Pelletier AJ, Bodary SC, Levinson AD. 1992. Signal transduction by the platelet integrin $\alpha_{\mathrm{IIb}} \beta_{3}$ : induction of calcium oscillations required for protein-tyrosine phosphorylation and ligand-induced spreading of stably transfected cells. Mol. Biol. Cell 3:989-98

Pelletier AJ, Kunicki T, Ruggeri ZM, Quaranta V. 1995. The activation state of the integrin $\alpha_{\mathrm{IIb}} \beta_{3}$ affects outside-in signals leading to cell spreading and focal adhesion kinase phosphorylation. J. Biol. Chem. 270:1813340

Peppelenbosch MP, Qiu RG, de Vries-Smits AM, Tertoolen LG, de Laat SW, et al. 1995. Rac mediates growth factor-induced arachidonic acid release. Cell 81:849-56

Petch LA, Bockholt SM, Bouton A, Parsons JT, Burridge K. 1995. Adhesion-induced tyrosine phosphorylation of the $\mathrm{p} 130^{\mathrm{scc}}$ substrate. J. Cell Sci. 108:1371-79

Pistor S, Chakraborty T, Walter U, Wehland
J. 1995. The bacterial actin nucleator protein ActA of Listeria monocytogenes contains multiple binding sites for host microfilament proteins. Curr. Biol. 5:517-25

Pleiman CM, Hertz WM, Cambier JC. 1994. Activation of phosphatidylinositol- $3^{\prime}$ kinase by Src-family kinase $\mathrm{SH} 3$ binding to the $\mathrm{p} 85$ subunit. Science 263:1609-12

Plopper GE, McNamee HP, Dike LE, Bojanowski K, Ingber DE. 1995. Convergence of integrin and growth factor receptor signaling pathways within the focal adhesion complex. Mol. Biol. Cell 6:1349-65

Pollard TD. 1995. Actin cytoskeleton. Missing link for intracellular bacterial motility? Curr. Biol. 5:837-40

Polte TR, Hanks SK. 1995. Interaction between focal adhesion kinase and Crk-associated tyrosine kinase substrate p130 ${ }^{\text {cas }}$. Proc. Natl. Acad. Sci. USA 92:10678-82

Prasad KV, Janssen O, Kapeller R, Raab M, Cantley LC, Rudd CE. 1993. Src-homology 3 domain of protein kinase $\mathrm{p} 59^{\mathrm{fyn}}$ mediates binding to phosphatidylinositol 3-kinase in T cells. Proc. Natl. Acad. Sci. USA 90:7366-70

Price LS, Norman JC, Ridley AJ, Koffer A. 1995. The small GTPases Rac and Rho as regulators of secretion in mast cells. Curr. Biol. 5:68-73

Rankin S, Morii N, Narumiya S, Rozengurt E. 1994. Botulinum C3 exoenzyme blocks the tyrosine phosphorylation of p125FAK and paxillin induced by bombesin and endothelin. FEBS Lett. 354:315-19

Rankin S, Rozengurt E. 1994. Platelet-derived growth factor modulation of focal adhesion kinase (p125FAK) and paxillin tyrosine phosphorylation in Swiss 3T3 cells. Bellshaped dose response and cross-talk with bombesin. J. Biol. Chem. 269:704-10

Re F, Zanetti A, Sironi M, Polentarutti N, Lanfrancone L, et al. 1994. Inhibition of anchorage-dependent cell spreading triggers apoptosis in cultured human endothelial cells. J. Cell Biol. 127:537-46

Reinhard J, Scheel AA, Diekmann D, Hall A, Ruppert C, Bahler M. 1995. A novel type of myosin implicated in signalling by rho family GTPases. EMBO J. 14:697-704

Reinhard M, Giehl K, Abel K, Haffner C, Jarchau T, et al. 1995. The proline-rich focal adhesion and microfilament protein VASP is a ligand for profilins. EMBO J. 14:1583-89

Reinhard M, Halbrugge M, Scheer U, Wiegand C, Jockusch BM, Walter U. 1992. The $46 / 50 \mathrm{kDa}$ phosphoprotein VASP purified from human platelets is a novel protein associated with actin filaments and focal contacts. EMBO J. 11:2063-70

Reinhard M, Jouvenal K, Tripier D, Walter 
U. 1995b. Identification, purification, and characterization of a zyxin-related protein that binds the focal adhesion and microfilament protein VASP (vasodilator-stimulated phosphoprotein). Proc. Natl. Acad. Sci. USA 92:7956-60

Ren XD, Bokoch GM, Traynor-Kaplan A, Jenkins GH, Anderson RA, Schwartz MA. 1996. Physical association of the small GTPase rho with a $68-\mathrm{kDa}$ phosphatidylinositol 4phosphate 5-kinase in Swiss 3T3 cells. Mol. Biol. Cell 7:435-42

Reynolds AB, Kanner SB, Wang HC, Parsons JT. 1989. Stable association of activated pp60 $0^{\mathrm{src}}$ with two tyrosine-phosphorylated cellular proteins. Mol. Cell. Biol. 9:3951-58

Richardson A, Parsons JT. 1995. Signal transduction through integrins: a central role for focal adhesion kinase? BioEssays 17:229-36

Richardson A, Parsons JT. 1996. A mechanism for regulation of the adhesion-associated potein tyrosine kinase $\mathrm{pp} 125^{\mathrm{FAK}}$. Nature 380:538-40

Ridley AJ. 1995. Rho-related proteins: actin cytoskeleton and cell cycle. Curr. Opin. Genet. Dev. 5:24-30

Ridley AJ, Comoglio PM, Hall A. 1995. Regulation of scatter factor/hepatocyte growth factor responses by Ras, Rac, and Rho in MDCK cells. Mol. Cell. Biol. 15:1110-22

Ridley AJ, Hall A. 1992. The small GTPbinding protein rho regulates the assembly of focal adhesions and actin stress fibers in response to growth factors. Cell 70:389-99

Ridley AJ, Hall A. 1994. Signal transduction pathways regulating Rho-mediated stress fibre formation: Requirement for a tyrosine kinase. EMBO J. 13:2600-10

Ridley AJ, Paterson HF, Johnston CL, Diekmann D, Hall A. 1992. The small GTPbinding protein rac regulates growth factorinduced membrane ruffling. Cell 70:401-10

Ridley AJ, Self AJ, Kasmi F, Paterson HF, Hall A, et al. 1993. rho family GTPase activating proteins $\mathrm{p} 190$, bcr and rhoGAP show distinct specificities in vitro and in vivo. EMBO J. 12:5151-60

Rodriguez Fernandez JL, Geiger B, Salomon D, Ben-Ze'ev A. 1993. Suppression of vinculin expression by antisense transfection confers changes in cell morphology, motility, and anchorage-dependent growth of 3 T3 cells. $J$. Cell Biol. 122:1285-94

Rodriguez Fernandez JL, Geiger B, Salomon D, Sabanay I, Zoller M, Ben-Ze'ev A. 1992. Suppression of tumorigenicity in transformed cells after transfection with vinculin cDNA. J. Cell Biol. 119:427-38

Romer LH, Burridge K, Turner CE. 1992. Signaling between the extracellular matrix and the cytoskeleton: tyrosine phosphorylation and focal adhesion assembly. Cold Spring Harbor Symp. Quant. Biol. 57:193-202

Romer LH, McLean N, Turner CE, Burridge K. 1994. Tyrosine kinase activity, cytoskeletal organization, and motility in human vascular endothelial cells. Mol. Biol. Cell 5:349-61

Ruhnau K, Gaertner A, Wegner A. 1989. Kinetic evidence for insertion of actin monomers between the barbed ends of actin filaments and barbed end-bound insertin, a protein purified from smooth muscle. J. Mol. Biol. 210:14148

Sabe H, Hata A, Okada M, Nakagawa H, Hanafusa H. 1994. Analysis of the binding of the Src homology 2 domain of Csk to tyrosinephosphorylated proteins in the suppression and mitotic activation of c-Src. Proc. Natl. Acad. Sci. USA 91:3984-88

Sadler I, Crawford AW, Michelsen JW, Beckerle MC. 1992. Zyxin and cCRP: two interactive LIM domain proteins associated with the cytoskeleton. J. Cell Biol. 119:1573-87

Sakai R, Iwamatsu A, Hirano N, Ogawa S, Tanaka T, et al. 1994. A novel signaling molecule, p130, forms stable complexes in vivo with $\mathrm{v}$-Crk and $\mathrm{v}$-Src in a tyrosine phosphorylation-dependent manner. $E M B O$ J. 13:3748-56

Salamero J, Fougereau M, Seckinger P. 1995. Internalization of B cell and pre-B cell receptors is regulated by tyrosine kinase and phosphatase activities. Eur. J. Immunol. 25:275764

Samuelsson SJ, Luther PW, Pumplin DW, Bloch RJ. 1993. Structures linking microfilament bundles to the membrane at focal contacts. J. Cell Biol. 122:485-96

Sanger JM, Mittal B, Pochapin MB, Sanger JW. 1987. Stress fiber and cleavage furrow formation in living cells microinjected with fluorescently labeled $\alpha$-actinin. Cell Motil. $C y$ toskelet. 7:209-20

Sasaki H, Nagura K, Ishino M, Tobioka H, Kotani K, Sasaki T. 1995. Cloning and characterization of cell adhesion kinase, a novel protein-tyrosine kinase of the focal adhesion kinase subfamily. J. Biol. Chem. 270:2120619

Sastry SK, Horwitz AF. 1993. Integrin cytoplasmic domains: mediators of cytoskeletal linkages and extra- and intracellular initiated transmembrane signaling. Curr. Opin. Cell Biol. 5:819-31

Sastry SK, Lakonishok M, Thomas DA, Muschler J, Horwitz AF. 1996. Integrin alpha subunit ratios, cytoplasmic domains, and growth factor synergy regulate muscle proliferation and differentiation. J. Cell Biol. 133:169-84 
Sato N, Funamaya N, Yonemura S, Tsukita S. 1992. A gene family consisting of ezrin, radixin and moesin. Its specific localization at actin filament/plasma membrane association sites. J. Cell Sci. 103:131-43

Satterwhite LL, Lohka MJ, Wilson KL, Scherson TY, Cisek LJ, et al. 1992. Phosphorylation of myosin-II regulatory light chain by cyclin-p34cdc2: a mechanism for the timing of cytokinesis. J. Cell Biol. 118:595-605

Schaller MD, Borgman CA, Cobb BS, Vines RR, Reynolds AB, Parsons JT. 1992. $p p 125^{\mathrm{FAK}}$ a structurally distinctive protein-tyrosine kinase associated with focal adhesions. Proc. Natl. Acad. Sci. USA 89:5192-96

Schaller MD, Hildebrand JD, Shannon JD, Fox JW, Vines RR, Parsons JT. 1994. Autophosphorylation of the focal adhesion kinase, pp125 $5^{\mathrm{FAK}}$, directs SH2-dependent binding of pp60 ${ }^{\text {src }}$. Mol. Cell. Biol. 14:1680-88

Schaller MD, Otey CA, Hildebrand JD, Parsons JT. 1995. Focal adhesion kinase and paxillin bind to peptides mimicking beta integrin cytoplasmic domains. J. Cell Biol. 130:1181-87

Schaller MD, Parsons JT. 1994. Focal adhesion kinase and associated proteins. Curr. Opin. Cell Biol. 6:705-10

Schaller MD, Parsons JT. 1995. pp125 $5^{\mathrm{FAK}}$ dependent tyrosine phosphorylation of paxillin creates a high-affinity binding site for Crk. Mol. Cell. Biol. 15:2635-45

Schlaepfer DD, Hanks SK, Hunter T, van der Geer P. 1994. Integrin-mediated signal transduction linked to Ras pathway by GRB2 binding to focal adhesion kinase. Nature 372:786-91

Schmeichel KL, Beckerle MC. 1994. The LIM domain is a modular protein-binding interface. Cell 79:211-19

Schwartz MA. 1993. Spreading of human endothelial cells on fibronectin or vitronectin triggers elevation of intracellular free calcium. J. Cell Biol. 120:1003-10

Schwartz MA, Both G, Lechene C. 1989. Effect of cell spreading on cytoplasmic $\mathrm{pH}$ in normal and transformed fibroblasts. Proc. Natl. Acad. Sci. USA 86:4525-29

Schwartz MA, Brown EJ, Fazeli B. 1993. A 50$\mathrm{kDa}$ integrin-associated protein is required for integrin-regulated calcium entry in endothelial cells. J. Biol. Chem. 268:19931-34

Schwartz MA, Cragoe EJ Jr, Lechene CP. 1990. $\mathrm{pH}$ regulation in spread cells and round cells. J. Biol. Chem. 265:1327-32

Schwartz MA, Denninghoff K. 1994. Alpha v integrins mediate the rise in intracellular calcium in endothelial cells on fibronectin even though they play a minor role in adhesion. $J$. Biol. Chem. 269:11133-37
Schwartz MA, Ingber DE, Lawrence M, Springer TA, Lechene C. 1991a. Multiple integrins share the ability to induce elevation of intracellular pH. Exp. Cell. Res. 195:533-35

Schwartz MA, Lechene C, Ingber DE. 1991b. Insoluble fibronectin activates the $\mathrm{Na} / \mathrm{H}$ antiporter by clustering and immobilizing integrin $\alpha_{5} \beta_{1}$, independent of cell shape. Proc. Natl. Acad. Sci. USA 88:7849-53

Schwartz MA, Schaller MD, Ginsberg MH. 1995. Integrins: emerging paradigms of signal transduction. Annu. Rev. Cell Biol. 11:549-99

Seckl M, Rozengurt E. 1993. Tyrphostin inhibits bombesin stimulation of tyrosine phosphorylation, c-fos expression, and DNA synthesis in Swiss 3 T3 cells. J. Biol. Chem. 268:9548-54

Sekine A, Fujiwara M, Narumiya S. 1989. Asparagine residue in the rho gene product is the modification site for botulinum ADPribosyltransferase. J. Biol. Chem. 264:86025

Sellers JR. 1991. Regulation of cytoplasmic and smooth muscle myosin. Curr. Opin. Cell Biol. 3:98-104

Serra-Pages C, Kedersha NL, Fazikas L, Medley Q, Debant A, Streuli M. 1995. The LAR transmembrane protein tyrosine phosphatase and a coiled-coil LAR-interacting protein co-localize at focal junctions. $E M B O$ J. 14:2827-38

Settleman J, Albright CF, Foster LC, Weinberg RA. 1992. Association between GTPase activators for Rho and Ras families. Nature 359:153-54

Seufferlein T, Rozengurt E. 1994. Lysophosphatidic acid stimulates tyrosine phosphorylation of focal adhesion kinase, paxillin, and p130. Signaling pathways and cross-talk with platelet-derived growth factor. J. Biol. Chem. 269:9345-51

Seufferlein T, Rozengurt E. 1995. Sphingosylphosphorylcholine rapidly induces tyrosine phosphorylation of $\mathrm{p} 125 \mathrm{FAK}$ and paxillin, rearrangement of the actin cytoskeleton and focal contact assembly. Requirement of p21rho in the signaling pathway. J. Biol. Chem. 270:24343-51

Shattil SJ, Haimovich B, Cunningham M, Lipfert L, Parsons JT, et al. 1994. Tyrosine phosphorylation of $\mathrm{pp} 125^{\mathrm{FAK}}$ in platelets requires coordinated signaling through integrin and agonist receptors. J. Biol. Chem. 269:14738-45

Shattil SJ, O'Toole T, Eigenthaler M, Thon V, Williams M, et al. 1995. Beta 3-endonexin, a novel polypeptide that interacts specifically with the cytoplasmic tail of the integrin beta 3 subunit. J. Cell Biol. 131:807-16 
Shibasaki F, Fukami K, Fukui Y, Takenawa T. 1994. Phosphatidylinositol 3-kinase binds to $\alpha$-actinin through the p85 subunit. Biochem. J. 302:551-57

Shimizu H, Ito M, Miyahara M, Ichikawa K, Okubo S, et al. 1994. Characterization of the myosin-binding subunit of smooth muscle myosin phosphatase. J. Biol. Chem. 269:30407-11

Shimo K, Gyotoku Y, Arimitsu Y, Kakiuchi T, Mizuguchi J. 1993. Participation of tyrosine kinase in capping, internalization, and antigen presentation through membrane immunoglobulin in BAL17 B lymphoma cells. FEBS Lett. 323:171-74

Shirazi A, Iizuka K, Fadden P, Mosse C, Somlyo AP, et al. 1994. Purification and characterization of the mammalian myosin light chain phosphatase holoenzyme. The differential effects of the holoenzyme and its subunits on smooth muscle. J. Biol. Chem. 269:31598606

Singer II, Kawka DW, Scott S, Mumford RA, Lark MW. 1987. The fibronectin cell attachment sequence Arg-Gly-Asp-Ser promotes focal contact formation during early fibroblast attachment and spreading. J. Cell Biol. 104:573-84

Singer II, Scott S, Kawka DW, Kazazis DM, Gailit J, Ruoslahti E. 1988. Cell surface distribution of fibronectin and vitronectin receptors depends on substrate composition and extracellular matrix accumulation. $J$. Cell Biol. 106:2171-82

Sinnett-Smith J, Zachary I, Valverde AM, Rozengurt E. 1993. Bombesin stimulation of p125 focal adhesion kinase tyrosine phosphorylation. Role of protein kinase $\mathrm{C}, \mathrm{Ca}^{2+}$ mobilization, and the actin cytoskeleton. J. Biol. Chem. 268:14261-68

Smalheiser NR, Kim E. 1995. Purification of cranin, a laminin binding membrane protein. Identity with dystroglycan and reassessment of its carbohydrate moieties. J. Biol. Chem. 270:15425-33

Smalheiser NR, Schwartz NB. 1987. Cranin: a laminin-binding protein of cell membranes. Proc. Natl. Acad. Sci. USA 84:6457-61

Solowska J, Guan JL, Marcantonio EE, Trevithick JE, Buck CA, Hynes RO. 1989. Expression of normal and mutant avian integrin subunits in rodent cells. J. Cell Biol. 109:85361. Erratum. 1989. J. Cell Biol. 109(4 Pt. 1): 1187

Somlyo AP, Somlyo AV. 1994. Signal transduction and regulation in smooth muscle. Nature 372:231-36. Erratum. 1994. Nature 372:812

Stasia MJ, Jouan A, Bourmeyster N, Boquet P, Vignais PV. 1991. ADP-ribosylation of a small size GTP-binding protein in bovine neutrophils by the $\mathrm{C} 3$ exoenzyme of Clostridium botulinum and effect on the cell motility. Biochem. Biophys. Res. Commun. 180:61522

Stoker M, O'Neill C, Berryman S, Waxman V. 1968. Anchorage and growth regulation in normal and virus-transformed cells. Int. J. Cancer 3:683-93

Streeter HB, Rees DA. 1987. Fibroblast adhesion to RGDS shows novel features compared with fibronectin. J. Cell Biol. 105:507-15

Suidan HS, Stone SR, Hemmings BA, Monard D. 1992. Thrombin causes neurite retraction in neuronal cells through activation of cell surface receptors. Neuron 8:363-75

Tachibana K, Sato T, D'Avirro N, Morimoto C. 1995. Direct association of $\mathrm{pp} 125^{\mathrm{FAK}}$ with paxillin, the focal adhesion-targeting mechanism of pp125 ${ }^{\mathrm{FAK}}$. J. Exp. Med. 182:1089-99

Takai Y, Sasaki T, Tanaka K, Nakanishi H. 1995. Rho as a regulator of the cytoskeleton. Trends Biochem. Sci. 20:227-31

Takaishi K, Kikuchi A, Kuroda S, Kotani K, Sasaki T, Takai Y. 1993. Involvement of rho p21 and its inhibitory GDP/GTP exchange protein (rho GDI) in cell motility. Mol. Cell. Biol. 13:72-79

Takaishi K, Sasaki T, Kato M, Yamochi W, Kuroda S, et al. 1994. Involvement of Rho p21 small GTP-binding protein and its regulator in the HGF-induced cell motility. Oncogene 9:273-79

Takeuchi K, Takahashi K, Abe M, Nishida W, Hiwada K, et al. 1991. Co-localization of immunoreactive forms of calponin with actin cytoskeleton in platelets, fibroblasts, and vascular smooth muscle. J. Biochem. 109:31116

Tan JL, Ravid S, Spudich JA. 1992. Control of nonmuscle myosins by phosphorylation. Annu. Rev. Biochem. 61:721-59

Tanaka S, Morishita T, Hashimoto Y, Hattori S, Nakamura S, et al. 1994. C3G, a guanine nucleotide-releasing protein expressed ubiquitously, binds to the Src homology domains of CRK and GRB2/ASH proteins. Proc. Natl. Acad. Sci. USA 91:3443-47

Tansey MG, Luby-Phelps K, Kamm KE, Stull JT. 1994. Ca(2+)-dependent phosphorylation of myosin light chain kinase decreases the $\mathrm{Ca}^{2+}$ sensitivity of light chain phosphorylation within smooth muscle cells. J. Biol. Chem. 269:9912-20

Tapley P, Horwitz A, Buck C, Duggan K, Rohrschneider L. 1989. Integrins isolated from Rous sarcoma virus-transformed chicken embryo fibroblasts. Oncogene 4:325-33

Theriot JA, Rosenblatt J, Portnoy DA, Goldschmidt-Clermont PJ, Mitchison TJ. 
1994. Involvement of profilin in the actinbased motility of L. monocytogenes in cells and in cell-free extracts. Cell 76:505-17

Thomas SM, Soriano P, Imamoto A. 1995. Specific and redundant roles of Src and Fyn in organizing the cytoskeleton. Nature 376:26771

Tomasek JJ, Haaksma CJ. 1991. Fibronectin filaments and actin microfilaments are organized into a fibronexus in Dupuytren's diseased tissue. Anat. Rec. 230:175-82

Tomasek JJ, Haaksma CJ, Eddy RJ, Vaughan MB. 1992. Fibroblast contraction occurs on release of tension in attached collagen lattices: dependency on an organized actin cytoskeleton and serum. Anat. Rec. 232:35968

Tominaga T, Sugie K, Hirata M, Morii N, Fukata J, et al. 1993. Inhibition of PMAinduced, LFA-1-dependent lymphocyte aggregation by ADP ribosylation of the small molecular weight GTP binding protein, rho. J. Cell Biol. 120:1529-37

Trinkle-Mulcahy L, Ichikawa K, Hartshorne DJ, Siegman MJ, Butler TM. 1995. Thiophosphorylation of the $130-\mathrm{kDa}$ subunit is associated with a decreased activity of myosin light chain phosphatase in alphatoxin-permeabilized smooth muscle. J. Biol. Chem. 270:18191-94

Tsukita S, Hieda Y. 1989. A new 82-kD barbed end-capping protein (radixin) localized in the cell-to-cell adherens junction: purification and characterization. J. Cell Biol. 108:236982

Turner CE. 1994. Paxillin: a cytoskeletal target for tyrosine kinases. BioEssays 16:47-52

Turner CE, Glenney JR Jr, Burridge K. 1990. Paxillin: a new vinculin-binding protein present in focal adhesions. J. Cell Biol. 111:1059-68

Turner CE, Miller JT. 1994. Primary sequence of paxillin contains putative $\mathrm{SH} 2$ and SH3 domain binding motifs and multiple LIM domains: identification of a vinculin and pp125Fak-binding region. J. Cell Sci. 107:1583-91

Turner CE, Pavalko FM, Burridge K. 1989. The role of phosphorylation and limited proteolytic cleavage of talin and vinculin in the disruption of focal adhesion integrity. J. Biol. Chem. 264:11938-44

Uddin S, Katzav S, White MF, Platanias LC. 1995. Insulin-dependent tyrosine phosphorylation of the vav protooncogene product in cells of hematopoietic origin. J. Biol. Chem. 270:7712-16

Ullrich A, Schlessinger J. 1990. Signal transduction by receptors with tyrosine kinase activity. Cell 61:203-12 van der Flier A, Kuikman I, Baudoin C, van der Neut R, Sonnenberg A. 1995. A novel beta 1 integrin isoform produced by alternative splicing: unique expression in cardiac and skeletal muscle. FEBS Lett. 369:340 44

Varner JA, Emerson DA, Juliano RL. 1995. Integrin $\alpha_{5} \beta_{1}$ expression negatively regulates cell growth: reversal by attachment to fibronectin. Mol. Biol. Cell 6:725-40

Vojtek AB, Cooper JA. 1995. Rho family members: activators of MAP kinase cascades. Cell 82:527-29

Volberg T, Geiger B, Citi S, Bershadsky AD. 1994. Effect of protein kinase inhibitor H-7 on the contractility, integrity, and membrane anchorage of the microfilament system. Cell Motil. Cytoskelet. 29:321-38

Vuori K, Hirai H, Aizawa S, Ruoslahti E. 1996. Induction of $\mathrm{p} 130^{\mathrm{cas}}$ signaling complex formation upon integrin-mediated cell adhesion: a role for src family kinases. Mol. Cell. Biol. 16:2606-13

Vuori K, Ruoslahti E. 1993. Activation of protein kinase $\mathrm{C}$ precedes $\alpha_{5} \beta_{1}$ integrinmediated cell spreading on fibronectin. $J$. Biol. Chem. 268:21459-62

Vuori K, Ruoslahti E. 1994. Association of insulin receptor substrate-1 with integrins. Science 266:1576-78

Vuori K, Ruoslahti E. 1995. Tyrosine phosphorylation of $\mathrm{p} 130^{\mathrm{cas}}$ and cortactin accompanies integrin-mediated cell adhesion to extracellular matrix. J. Biol. Chem. 270:22259-62

Wachsstock DH, Wilkins JA, Lin S. 1987. Specific interaction of vinculin with $\alpha$-actinin. Biochem. Biophys. Res. Commun. 146:554 60

Watanabe G, Saito Y, Madaule P, Ishizaki T, Fujisawa K, et al. 1996. Protein kinase N (PKN) and PKN-related protein rhophilin as targets of small GTPase rho. Science 271:645-48

Weber K, Groeschel-Stewart U. 1974. Antibody to myosin: the specific visualization of myosin-containing filaments in nonmuscle cells. Proc. Natl. Acad. Sci. USA 71:456165

Weekes J, Barry ST, Critchley DR. 1996. Acidic phospholipids inhibit the intramolecular association between the $\mathrm{N}$ - and C-terminal regions of vinculin, exposing actin-binding and protein kinase $\mathrm{C}$ phosphorylation sites. Biochem. J. 314:827-32

Wehland J, Osborn M, Weber K. 1974. Cellto-substratum contacts in living cells: a direct correlation between the interferencereflexion and indirect-immunofluorescence microscopy in using antibodies against actin and $\alpha$-actinin. J. Cell Sci. 37:257-73

Weigt C, Gaertner A, Wegner A, Korte H, Meyer 
HE. 1992. Occurrence of an actin-inserting domain in tensin. J. Mol. Biol. 227:593-95

Weng Z, Taylor JA, Turner CE, Brugge JS, Seidel-Dugan C. 1993. Detection of Src homology 3-binding proteins, including paxillin, in normal and $\mathrm{v}$-Src-transformed Balb/c 3T3 cells. J. Biol. Chem. 268:1495663

Wilkins JA, Risinger MA, Coffey E, Lin S. 1987. Purification of a vinculin binding protein from smooth muscle. J. Cell Biol. 104:A130

Wilkins JA, Risinger MA, Lin S. 1986. Studies on proteins that co-purify with smooth muscle vinculin: identification of immunologically related species in focal adhesions of nonmuscle and Z-lines of muscle cells. $J$. Cell Biol. 103:1483-94

Wilson L, Carrier MJ, Kellie S. 1995. pp125 $5^{\text {FAK }}$ tyrosine kinase activity is not required for the assembly of F-actin stress fibres and focal adhesions in cultured mouse aortic smooth muscle cells. J. Cell Sci. 108:2381-91

Winder SJ, Walsh MP. 1990. Smooth muscle calponin. Inhibition of actomyosin MgATPase and regulation by phosphorylation. $J$. Biol. Chem. 265:10148-55

Woods A, Couchman JR. 1992. Protein kinase $\mathrm{C}$ involvement in focal adhesion formation. J. Cell Sci. 101:277-90

Woods A, Couchman JR. 1994. Syndecan 4 heparan sulfate proteoglycan is a selectively enriched and widespread focal adhesion component. Mol. Biol. Cell 5:183-92

Woods A, Couchman JR, Johansson S, Hook M. 1986. Adhesion and cytoskeletal organisation of fibroblasts in response to fibronectin fragments. $E M B O$ J. 5:665-70

Xing Z, Chen HC, Nowlen JK, Taylor SJ, Shalloway D, Guan JL. 1994. Direct interaction of $\mathrm{v}$-Src with the focal adhesion kinase mediated by the Src SH2 domain. Mol. Biol. Cell 5:413-21

Xu L, Owens LV, Sturge GC, Yang X, Liu ET, et al. 1996. Attenuation of the expression of the focal adhesion kinase induces apoptosis in tumor cells. Cell Growth Diff. 7:413-18

Yamada KM, Miyamoto S. 1995. Integrin transmembrane signaling and cytoskeletal control. Curr. Opin. Cell Biol. 7:681-89

Yamakita Y, Yamashiro S, Matsumura F. 1994. In vivo phosphorylation of regulatory light chain of myosin II during mitosis of cultured cells. J. Cell Biol. 124:129-37

Yamashiro S, Yamakita Y, Hosoya H, Matsumura F. 1991. Phosphorylation of nonmuscle caldesmon by p34cdc2 kinase during mitosis. Nature 349:169-72

Yamashiro S, Yamakita Y, Ishikawa R, Matsumura F. 1990. Mitosis-specific phosphorylation causes $83 \mathrm{~K}$ non-muscle caldesmon to dissociate from microfilaments. Nature 344:675-78

Yamashiro S, Yamakita Y, Yoshida K, Takiguchi K, Matsumura F. 1995. Characterization of the $\mathrm{COOH}$ terminus of nonmuscle caldesmon mutants lacking mitosisspecific phosphorylation sites. J. Biol. Chem. 270:4023-30

Ylanne J, Chen Y, O'Toole TE, Loftus JC, Takada Y, Ginsberg MH. 1993. Distinct functions of integrin $\alpha$ and $\beta$ subunit cytoplasmic domains in cell spreading and formation of focal adhesions. J. Cell Biol. 122:22333

Zachary I, Sinnett-Smith J, Rozengurt E. 1992. Bombesin, vasopressin, and endothelin stimulation of tyrosine phosphorylation in Swiss 3T3 cells. Identification of a novel tyrosine kinase as a major substrate. J. Biol. Chem. 267:19031-34

Zachary I, Sinnett-Smith J, Turner CE, Rozengurt E. 1993. Bombesin, vasopressin, and endothelin rapidly stimulate tyrosine phosphorylation of the focal adhesion-associated protein paxillin in Swiss 3 T3 cells. J. Biol. Chem. 268:22060-65

Zhang Z, Vuori K, Reed JC, Ruoslahti E. 1995. The alpha-5-beta-1 integrin supports survival of cells on fibronectin and up-regulates Bcl2 expression. Proc. Natl. Acad. Sci. USA 92:6161-65

Zhidkova NI, Belkin AM, Mayne R. 1995. Novel isoform of beta 1 integrin expressed in skeletal and cardiac muscle. Biochem. Biophys. Res. Commun. 214:279-85

Zhu X, Assoian RK. 1995. Integrin-dependent activation of MAP kinase: a link to shapedependent cell proliferation. Mol. Biol. Cell 6:273-82

Zigmond SH, Otto JJ, Bryan J. 1979. Organization of myosin in a submembranous sheath in well-spread human fibroblasts. Exp. Cell. Res. 119:205-19 
RT AND ROUTING OF NUCLEUS-ENCODED CHLORO ROTEINS, Kenneth Cline, Ralph Henry

\section{AL-MEDIATED SORTING OF MEMBRANE PROTEINS}

THE ENDOPLASMIC RETICULUM AND THE GOLGI A Rohan D. Teasdale, Michael R. Jackson

ECEPTOR Signaling PATHWAYS, Jennifer V. Schn Christopher A. Bradfield

KINE RECEPTOR SIGNAL TRANSDUCTION AND THE HematopoIetic Cell DEVElopMENT, Stephanie Hong Wu, Merav Socolovsky, Ursula Klingmuller, Constantinescu, Harvey F. Lodish

v: General Principles from Studies in Yeast, Kathr Ayscough, David G. Drubin

NIZING SPATIAL PATTERN IN LIMB DEVELOPMEN1 Brook, Fernando J. Diaz-Benjumea, Stephen M. C CEPTORS AND THEIR INTERACTIONS WITH IMMUN Malini Raghavan, Pamela J. Bjorkman

S-TALK BETWEEN BACTERIAL PATHOGENS AND T Cells, Jorge E. Galán, James B. Bliska

IISITION OF IDENTITY IN THE DEVELOPING LEAF, $A$ Sylvester, Laurie Smith, Michael Freeling

TIC Chromosome Condensation, Douglas Kosh Alexander Strunnikov

XISOME PROLIFERATOR-ACTIVATED RECEPTORS: 
E-FunCTION ANALYSIS OF THE MOTOR DOMAIN C sIN, Kathleen M. Ruppel, James A. Spudich ISIS AND MOLECULAR SORTING, Ira Mellman L and Cell-Cell Fusion, $L . D$. Hernandez, $L . R$ zan, T. G. Wolfsberg, J. M. White

FUSION IN THE YEAST Saccharomyces cerevisiae,

\section{Rose}

OTHER RECOGNITION SEQUENCES FOR INTEGRINS Ruoslahti

$\operatorname{dex}$

e Index of Contributing Authors, Volumes 8-12

e Index of Chapter Titles, Volumes 8-12 